\section{ESPAÑA Y GRAN BRETAÑA EN LA PRIMERA GUERRA MUNDIAL: UNA COLABORACIÓN BUSCADA Y DESEADA MÁS ALLÁ DE LA NEUTRALIDAD}

\author{
María Dolores Elizalde \\ C.S.I.C. \\ lola.elizalde@cchs.csic.es
}

\author{
SPAIN AND GREAT BRITAIN IN THE \\ FIRST WORLD WAR: \\ A COLLABORATION SEARCHED AND \\ DESIRED BEYOND THE NEUTRALITY
}

Recibido: 19/07/2016 - Aceptado: 05/10/2016

\section{Cómo citar este artículo/Citation:}

María Dolores ELIZALDE (2017), “España y Gran Bretaña en la Primera Guerra Mundial: una colaboración buscada y deseada más allá de la neutralidad", Hispania Nova, 15, págs. 316-349, DOI: https://doi.org/10.20318/hn.2017.3492
Copyright: C HISPANIA NOVA es una revista debidamente registrada, con ISSN 1138-7319 y Depósito Legal M 9472-1998. Los textos publicados en esta revista están -si no se indica lo contrario- bajo una licencia Reconocimiento-Sin obras derivadas 3.0 España de Creative Commons. Puede copiarlos, distribuirlos y comunicarlos públicamente siempre que cite su autor y la revista y la institución que los publica y no haga con ellos obras derivadas. La licencia completa se puede consultar en: http://creativecommons.org/licenses/by-nd/3.0/es/deed.es
Resumen: Con ocasión del centenario de la Primera Guerra Mundial, se está produciendo una revisión historiográfica en la que se replantean los conceptos, prácticas y contenidos de la neutralidad. Distintas historiografías analizan hoy qué significó realmente para sus países la neutralidad, porqué eligieron la opción de apartarse de un conflicto general, qué presiones recibieron para favorecer la posición de los distintos combatientes, qué respuestas dieron ante esas presiones, y qué consecuencias tuvieron las distintas posiciones.

Como es bien sabido, ante el estallido de la Gran Guerra, España eligió la neutralidad. Sin embargo, en un enfrentamiento de tales dimensiones era imposible que ningún país europeo permaneciera ajeno al conflicto. Ni los sucesivos gobiernos españoles, ni sus autoridades, ni sectores muy diversos de la sociedad española mantuvieron una estricta y equidistante neutralidad. Tampoco los países beligerantes fueron indiferentes a la actitud que adoptara España y a las ventajas que podría ofrecer su colaboración en la contienda.
Desde esas perspectivas, en este trabajo se va a analizar la consideración británica de España durante la Primera Guerra Mundial, así como los esfuerzos que realizaron los representantes de Gran Bretaña para ganarse el apoyo español, más allá de su teórica neutralidad. Para ello se estudian dos momentos especialmente interesantes, 1914 y 1917, en los cuales se planteó la posibilidad de que España entrara en guerra, evaluando el interés que tal circunstancia pudo tener para Gran Bretaña y las acciones emprendidas por los británicos para conseguir el apoyo español.

Palabras clave: Primera Guerra Mundial, España, Gran Bretaña, neutralidad, relaciones internacionales. 
Abstract: On the centenary of the First World War, it is taking a historiographical review in which the concepts, practices and content of neutrality are reframed. Different historiographies discussed today what really meant for their countries neutrality, why they chose the option of stand aside from a general conflict, what pressures they had to favor the position of the various combatants, what answers given to these pressures, and what consequences had the different attitudes. .

As is well known, in the face of the outbreak of the Great War, Spain chose neutrality. However, in a clash of such dimensions it was impossible for any European country to remain outside the conflict. Neither the successive Spanish governments, or its authorities, or very different sectors of Spanish society maintained an strict neutrality and equidistance. Nor the belligerent countries were indifferent to the attitude adopted by Spain and the advantages their collaboration could offer in the fight.
From those perspectives, this paper will be analyzed British consideration of Spain during the First World War as well as the efforts made by the representatives of Great Britain to win the Spanish support, beyond its theoretical neutrality. For this, they will be studied two especially interesting moments, 1914 and 1917, in which the possibility that Spain entered the war was raised, evaluating the interest that this situation could have for Britain and the actions taken by the British to get Spanish support.

Keywords: First World War, Spain, Great Britain, neutrality, international relations 


\section{ESPAÑA Y GRAN BRETAÑA EN LA PRIMERA GUERRA MUNDIAL: UNA COLABORACIÓN BUSCADA Y DESEADA MÁS ALLÁ DE LA NEUTRALIDAD}

\section{Replanteamiento de la neutralidad española en la Primera Guerra Mundial}

Ante el estallido de la Primera Guerra Mundial, España eligió la neutralidad. Sin embargo, en un conflicto de tales dimensiones era imposible que ningún país europeo permaneciera ajeno a la guerra. $\mathrm{Ni}$ los sucesivos gobiernos españoles, ni sus autoridades, ni sectores muy diversos de la sociedad española mantuvieron una estricta y equidistante neutralidad. Tampoco los países beligerantes fueron indiferentes a la actitud que adoptara España y a las ventajas que podría ofrecer su colaboración en la contienda. Desde esas perspectivas, en este trabajo se va a analizar la consideración británica de España durante la Primera Guerra Mundial, así como los esfuerzos que realizaron los representantes de Gran Bretaña para ganarse el apoyo español, más allá de su teórica neutralidad ${ }^{1}$. El cuestionamiento sobre el interés de la entrada de España en la guerra fue un largo debate mantenido en aquellos años bélicos. Todavía en 1918, un diplomático británico seguía planteando a sus superiores: "Si la neutralidad de España -por así llamarla- se mantiene..." y debatía a continuación las ventajas e inconvenientes que tendrían las tres alternativas más posibles: que España mantuviera la supuesta neutralidad inicial, que rompiera las relaciones con Alemania, o que participara al lado de los combatientes. ${ }^{2} \mathrm{~A}$ fin de analizar los términos del debate, y lo que éstos revelan sobre la valoración británica de España, vamos a estudiar dos momentos especialmente interesantes, 1914 y 1917, en los cuales se planteó la posibilidad de que España entrara en guerra, evaluando el interés que tal circunstancia pudo tener para Gran Bretaña.

La investigación se enmarca dentro de la actual tendencia historiográfica que, con ocasión del centenario de la Primera Guerra Mundial, se está replanteando los conceptos, prácticas y contenidos de la neutralidad. ${ }^{3}$ Distintas historiografías revisan hoy qué significó realmente para sus países la neutralidad,

\footnotetext{
${ }^{1}$ Sobre esta misma temática, pero desde un enfoque y objetivos diferentes, la autora de este texto publicó hace años dos artículos, ahora corregidos y ampliados tras la aparición de nueva bibliografía y el desarrollo de nuevas investigaciones, María Dolores ELIZALDE, "Los servicios de inteligencia británicos en España durante la Primera Guerra Mundial", Revista de Historia Militar, Número Extraordinario (2005), pp. 227-258. "Les relations entre la Grande Bretagne et l'Espagne pendant la Première Guerre Monsiale par le biais des Services d'Intelligence Britanniques", Guerres Mondiales et conflits contemporaines, Revue d'Histoire, 226 (2007), pp.23-36.

2 The National Archives (TNA), Kew, United Kingdom, FO 1011/117, Percy Loraine Papers, Correspondence when in Spain, Carta de Percy Loraine a Lord Hambro, 9 de agosto de 1918. En este trabajo se va a seguir el criterio de traducir del inglés al castellano las citas incluidas en el texto y respetar la versión original en las notas.

3 Johan den HERTOG and Samuël KRUIZINGA (ed.), Caught in the Middle. Neutrals, neutrality, and the First World War. Amsterdam, Aksant Academic Publishers-Amsterdam University Press, 2011. Troy PADDOCK, (ed.), World War I and Propaganda. Brill, Leiden, 2014. José-Leonardo RUIZ SÁNCHEZ, Inmaculada CORDERO OLIVERO y Carolina GARCÍA SANZ (eds.), Shaping Neutrality throughout the First World War. Sevilla, Editorial Universidad de Sevilla, 2015. James E. KITCHEN , Alisa MILLER and Laura ROWE (ed.), Other Combatants, Other Fronts. Competing
} 
porqué eligieron la opción de apartarse de un conflicto general, qué presiones recibieron para favorecer la posición de los distintos combatientes, qué respuestas dieron ante esas presiones, hasta qué punto fueron, o no, "neutrales aliados" ${ }^{4}$ o qué repercusiones posteriores tuvo aquella inhibición bélica ${ }^{5}$.

En esa misma línea, pero dentro del análisis del trabajo realizado en España durante la contienda por los distintos servicios de inteligencia, se insertan los recientes trabajos de Fernando García Sanz, Carolina García Sanz, Eduardo González Calleja y Paul Aubert, que han demostrado las continuas injerencias de representantes de distintos países para que los recursos, los apoyos y las posiciones españolas durante la guerra fueran favorables a sus intereses ${ }^{6}$. El primero de estos autores afirma incluso que España fue oficialmente neutral porque no movilizó sus tropas, pero que en la práctica no lo fue "porque no le dejaron y porque tampoco quiso serlo". En un país con significativos recursos mineros, una interesante situación estratégica y en cuyas aguas se libró una importante guerra naval y submarina, distintos países emprendieron numerosas iniciativas diplomáticas y desarrollaron unas redes de espionaje y contraespionaje tan importantes que acabaron por convertir la Península, Baleares y Canarias en un "nuevo y distinto frente de combate" ${ }^{7}$. Desde una perspectiva similar, también González Calleja y Aubert subrayan que fueron los propios beligerantes quienes eligieron el territorio de la Península "para librar una guerra de espionaje, sabotaje y propaganda, una guerra invisible, sin frentes", destinada a favorecer sus intereses en la contienda y a mejorar su imagen a fin mejorar las condiciones de la paz ${ }^{8}$.

Histories of the First World War. Cambridge, 2011. Fernando GARCÍA SANZ, España en la Gran Guerra. Espías, diplomáticos y traficantes. Barcelona, Galaxia Gutenberg, 2014, obra en la cual, más allá del título, se hace un análisis en profundidad de cómo y porqué en España no fue posible la neutralidad y hasta qué punto se desvirtuó tal realidad.

4 Javier PONCE, "La política exterior española de 1907 a 1920: entre el regeneracionismo de intenciones y la neutralidad condicionada”, Historia Contemporánea, 34 (2007), pp. 93-115, cita en p. 103.

${ }^{5}$ Maartje ABBENHUIS, The Art of Staying Neutral: The Netherlands in the First World War, 1914-1918. Amsterdam, Amsterdam University Press, 2006. Wim KLINKERT, Defending Neutrality: The Netherlands prepares for War, 19001925, Brill, 2013. Los siguientes artículos en el libro de HERTOG and KRUIZINGA (eds.), Caught in the Middle...: Louis CLERC, "The Hottest Places in Hell? Finnish and Nordic neutrality from the perspective of French foreign policy, 1900-1940", pp. 139-153. Karen GRAM-SKJOLDAGER, "The Other End of Neutrality. The First World War, the League of Nations, and Danish neutrality", pp.155-172. Johan den HERTOG, "Dutch Neutrality and the Value of Legal Argumentation", pp. 15-33. Samuël KRUIZINGA, "Not Neutrality. The Dutch Government, the Netherlands Oversea Trust Company and the entente blockade of Germany, 1914-1918", pp. 85-103. Javier PONCE, "Spanish Neutrality during the First World War", pp. 53-65. Roman ROSSFELD, Thomas BUOMBERGER, and Patrick KURY (eds.), La Suisse et la Grande Guerre. Hier+ Jetzt, 2014. Javier PONCE, "Neutrality and submarine warfare: Germany and Spain during the First World War", War \& Society, 34:4 (2015), pp. 287-300. Francisco ROMERO, "Fatal Neutrality: Pragmatism or Capitulation? Spain's Foreign Policy during the Great War", European History Quarterly, Vol. 33, No. 3 (2003), pp. 291-315. Carolina GARCÍA SANZ "Repensar la neutralidad de la Gran Guerra. Una lectura en clave europea", en Pedro RUIZ TORRES, (ed.), Volver a pensar el mundo de la Gran Guerra pp. 183208. Carolina GARCÍA SANZ y Maximiliano FUENTES CODERA, "Toward New Approaches to Neutrality in the First World War: Rethinking the Spanish Case-Study", en RUIZ SÁNCHEZ, CORDERO OLIVERO y C. GARCÍA SANZ (eds.), Shaping Neutrality..., pp. 39-62.

${ }^{6}$ Carolina GARCÍA SANZ, La Primera Guerra Mundial en el Estrecho de Gibraltar: economía, política y relaciones internacionales. Madrid, CSIC, 2011. Fernando GARCÍA SANZ, España en la Gran Guerra. Espías, diplomáticos y traficantes. Barcelona, Galaxia Gutenberg, 2014. Eduardo GONZÁLEZ CALLEJA y Paul AUBERT, Nidos de espías. España, Francia y la Primera Guerra Mundial, 1914-1919. Madrid, Alianza Editorial, 2014.

${ }^{7}$ F. GARCÍA SANZ, España en la Gran Guerra..., p. 15-16.

${ }^{8}$ GONZÁLEZ CALLEJA y AUBERT, Nidos de espías..., p. 19. 


\section{Consideración bRITÁNICA de EsPaña dURANTE LA PRIMERA GUERRA MUNDIAL}

¿Quiere esto decir que Gran Bretaña trabajó para que España no fuera neutral? ¿Le interesó más que España fuera neutral o combatiente a su lado? ¿Qué consideración mereció España durante la Primera Guerra Mundial a ojos de los británicos?

Inicialmente, dentro de la perspectiva asumida por todos de que la guerra iba a ser breve, y no estando España obligada por ningún compromiso internacional a declararse beligerante, se le atribuyó una importancia secundaria, condicionada por varios factores. En primer lugar, tanto la Marina como el Ejército español eran pequeños y no estaban bien preparados, por lo que su contribución militar al esfuerzo bélico sería escasa en comparación con la ayuda que requeriría defender su territorio. Era preferible, pues, ganar su apoyo, pero como país neutral. En segundo lugar, Gibraltar, que era una base estratégica fundamental para el control del Estrecho y del Mediterráneo, ya estaba en manos inglesas y por ello los británicos consideraron que no sería necesaria una segunda plataforma en la Península, a pesar de que el Almirantazgo insistió en que les interesaba la colaboración española en la guerra. Además, Gran Bretaña se había asegurado la alianza y el apoyo portugués, con lo cual controlaba la vertiente atlántica de la Península y podía utilizar las islas de Madeira, Cabo Verde y Azores como bases de carboneo y comunicaciones en pleno Atlántico, lo cual disminuía el atractivo del suelo español. Por otra parte, la especial relación que unía a Gran Bretaña y a Estados Unidos se tradujo en una pronta colaboración estadounidense con los aliados, lo cual aseguró el suministro de muchos productos que en caso contrario Gran Bretaña hubiera tenido que buscar en otros lugares, uno de los cuales hubiera sido España.

Sin embargo, esas consideraciones variaron en el transcurso de la guerra por diversas circunstancias. El conflicto fue mucho más largo de lo esperado, lo cual provocó que la situación se fuera complicando para todos los contrincantes y tuvieran que buscar nuevos apoyos y recursos que al principio no se habían considerado imprescindibles. Además, la importancia estratégica de España se incrementó, especialmente a partir de 1916, al desarrollarse en aguas españolas muchas operaciones de la guerra submarina y al creerse que los alemanes encontraban grandes apoyos en sus costas. Los británicos declararon objetivo prioritario acabar con los ataques submarinos en España, controlar las operaciones, comunicaciones y movimientos de la flota alemana en la Península y evitar que España pudiera servir de base, refugio o lugar de abastecimiento y carboneo para buques y submarinos alemanes. Por otra parte, la ofensiva submarina alemana estaba dificultando el transporte a través del Atlántico, lo cual perjudicaba, y a menudo incluso impedía, la ayuda material de los Estados Unidos. Todo ello provocó que, a medida que la guerra se fue prolongando, disminuyeran los recursos de los beligerantes y se redujeran los países donde se podían aprovisionar. A partir de un momento, Gran Bretaña tuvo una necesidad absoluta de hierro y de otros minerales con los que seguir alimentando la maquinaria bélica. Dadas las dificultades en el transporte de los productos norteamericanos, el lugar más rápido y barato donde podía encontrar ese hierro era España. También importaban otros productos pero el caso del hierro era esencial. De igual relevancia era encontrar barcos de bandera neutral en los que se pudiera transportar la carga hasta el lugar de destino, con lo cual los mercantes españoles adquirieron un nuevo interés. Al tiempo, con la prolongación de la guerra, el impacto de la contienda repercutió cada vez con más fuerza en los archipiélagos y en las colonias españolas, incrementándose en interés por los territorios extrapeninsulares, desde Baleares a Canarias, 
desde Marruecos a Guinea o Fernando Po ${ }^{9}$. Por todas estas razones, en el transcurso la guerra, España fue adquiriendo una importancia creciente en los esquemas británicos.

En la postura de Gran Bretaña hacia España pesó también la actitud adoptada por Estados Unidos. En un principio, el gobierno americano consideró la colaboración marítima española en la guerra no sería relevante debido al estado de su Marina. Sin embargo, España podía tener valor debido a su estratégica posición, ya que era un país situado en el flanco atlántico de las rutas marítimas aliadas, lo cual podría tener su utilidad, y también debido al comportamiento que adoptara respecto a Alemania. A los estadounidenses les preocupó una posible ayuda española a los países centroeuropeos, dadas las simpatías que importantes sectores de la población tenían hacia esas potencias. No obstante, consideraron que, debido a su posición geográfica, España no estaba en situación de enviar cantidades considerables de alimentos ni de productos manufacturados a los países centrales porque no tenía rutas directas de comunicación terrestre y las marítimas estaban bien vigiladas por los aliados. La única forma en que podrían abastecerles sería a través de submarinos, y eso era lo verdaderamente se tendría que vigilar. Era necesario evitar que España prestara ayuda a los submarinos alemanes que tanto daño estaban haciendo a los barcos aliados y vigilar la utilización alemana de estaciones de radio españolas. De igual forma, los estadounidenses, en absoluta concordancia con los británicos, señalaron que sería necesario contrarrestar la influencia que la potente red de propaganda alemana ejercía en España. A estas tareas se dedicaron muchos de sus agentes destinados en la Península y en sus archipiélagos ${ }^{10}$.

Ahora bien, en el transcurso de la guerra España adquirió un nuevo valor, también para el gobierno americano debido a la común necesidad de intercambios de productos ${ }^{11}$. Gran Bretaña necesitaba hierro, Estados Unidos pirita y los ejércitos aliados traviesas de madera, mulas, caballos y otras provisiones. Parte de ese material podría traerse de Estados Unidos, pero la cantidad de buques hundidos en el Atlántico en un momento especialmente crítico hizo que la asistencia desde España, situada en una buena posición estratégica para ello, pareciera especialmente interesante. Además, los españoles necesitaban carbón británico y petróleo y algodón americano para su floreciente industria textil, lo cual hizo posible un acuerdo

\footnotetext{
${ }^{9}$ GONZÁLEZ CALLEJA y AUBERT, Nidos de espías..., p. 211; Javier PONCE, Canarias en la Gran Guerra, 1914-1918: estrategia y diplomacia. Un estudio sobre la política exterior de España. Las Palmas de Gran Canaria, Ediciones del Cabildo de Gran Canaria, 2006.

${ }^{10}$ Thomas A. BAILEY, The policy of the United States toward the Neutrals, 1917-1918, Baltimore, The Johns Hopkins Press, 1942. José Antonio MONTERO JIMÉNEZ, "Neutrality and Leadership: The United States, Spain and World War I", en RUIZ SÁNCHEZ, CORDERO OLIVERO y C. (eds.), Shaping Neutrality..., pp. 247-277.

${ }^{11}$ Responsables del ejército norteamericano manifestaron en noviembre de 1917 que la entrada de España en guerra reforzaría el frente occidental, garantizaría el abastecimiento, aseguraría el suministro de hierro y pondría fin a las actividades de barcos y submarinos alemanes en la costa española", BAILEY, The policy of the United States..., p. 237. El gobierno de Estados Unidos presionó a España con el embargo a fin de obtener una actitud amistosa hacia sus intereses, pero no negoció su entrada en la guerra. Aún así el Departamento de Estado escribió al embajador americano en Madrid, en septiembre de 1918 informándole de que "este gobierno no va a ejercer la menor influencia en la actuación de España. Sin embargo, si España decide entrar en guerra con Alemania, los Estados Unidos la apoyarán y asistirán en todas las formas. Esta instrucción es para su información y guía, y no para la transmisión formal al Gobierno español", Foreign Relations of the United States, (FRUS), 1918, Supp.1, II, p. 1726. EI embajador americano mantuvo entonces una conversación informal con el ministro de exteriores español, en la cual le trasmitió que si el gobierno español, por sus propias razones, decidía convertirse en beligerante, su gobierno le ayudaría en sus necesidades económicas. Conversación informal del embajador Willard con el Ministro de Exteriores español, FRUS, 1918, Supp.1, pp. 1717-1724.
} 
beneficioso para todas las parte partes. Los americanos trabajaron junto a los británicos para asegurar que España se avenía a ese intercambio de productos ${ }^{12}$. Fue fácil, pues, concertar los intereses británicos y norteamericanos a fin de que España fuera un neutral favorable a su causa, suministrara los materiales que necesitaban, no apoyara a Alemania ni facilitara la labor de sus submarinos.

En cualquier caso, fuera cual fuera la posición oficial de España, y aunque ello implicara un status y unas prácticas definidas por las leyes internacionales, se ha señalado también que la importante presencia de Gran Bretaña en Gibraltar y las muchas acciones desde allí centralizadas que tuvieron como escenario la Península y sus archipiélagos hicieron imposible una verdadera neutralidad por parte de España ${ }^{13}$.

\section{OBJETIVOS BRITÁNICOS EN ESPAÑA}

El esfuerzo británico en España durante la Primera Guerra Mundial tuvo varios objetivos. En primer lugar, se señaló un objetivo político encaminado a informar sobre la política española, tratar de influir en su desarrollo y atraer al gobierno y al conjunto de la población española hacia la causa aliada. Para ello era necesario conocer bien la situación interna del país, a fin de calibrar de qué manera podía afectar al desarrollo de la contienda, y advertir de la actitud del gobierno español hacia los beligerantes en cada momento de la guerra. A tal objeto, los representantes británicos debían entablar contactos regulares con el mundo de la política y con los sectores más influyentes del país. Se trataba de mantener informado a su gobierno de la evolución de la política interna, comentar los posibles cambios en puestos ministeriales, enjuiciar los acontecimientos más destacados y las repercusiones que pudieran tener sobre sus intereses, contrarrestar las acciones que pudieran ser negativas y procurar impulsar líneas de acción que les fueran favorables.

En segundo lugar, se definieron una serie de objetivos económicos encaminados tanto al bloqueo comercial del enemigo como a garantizar el abastecimiento de una serie de productos necesarios para el esfuerzo bélico británico, temas ambos directamente relacionados con la supremacía marítima ${ }^{14}$. Para conseguir el segundo de esos objetivos, los británicos intensificaron sus relaciones con el mundo de las finanzas, el comercio y los transportes españoles, a fin de asegurar una red de suministro de alimentos, materias primas, recursos mineros y productos químicos e industriales ${ }^{15}$. Materiales todos ellos que había que conseguir trasladar a Gran Bretaña en barcos que no pudieran ser interceptados por los alemanes. A tal fin incrementaron sus relaciones con compañías tales como Altos Hornos de Vizcaya, Phoenicia Mines

\footnotetext{
${ }^{12}$ BAILEY, The policy of the United States..., pp. 275-276.

${ }^{13}$ C. GARCÍA SANZ, La Primera Guerra Mundial..., pp. 290-306.

${ }^{14}$ GONZÁLEZ CALLEJA y AUBERT, Nidos de espías..., pp. 81-89.

15 Diversos autores han analizado los intereses económicos británicos en España en el período en torno a la Primera Guerra Mundial, evidenciando el alto grado de implicación en sectores clave como la minería, la agricultura y los vinos, los transportes, la energía o los servicios públicos. Entre esos autores, Teresa TORTELLA, $A$ guide to sources of information on Foreign Investments in Spain, 1870-1914. Ámsterdam, International Institute of Social History, 2000. David AVERY, Nunca en el cumpleaños de la Reina Victoria: Historia de las Minas de Rio Tinto. Barcelona, Labor, 1985. Francisco COMín, 150 años de historia de los ferrocarriles españoles. Madrid, Anaya, 1998. Leandro PRADOS DE LA ESCOSURA, De imperio a Nación: crecimiento y atrás económico en España, 17801930. Madrid, Alianza, 1988. JM. VALDALISO, Los navieros vascos y la marina mercante en España, 1860-1935. Bilbao, Instituto Vasco de la Administración Pública, 1991. Sebastián COLL, El carbón en España, $1770-1961$. Madrid, Turner, 1987. Un buen estado de la cuestión en C. GARCÍA SANZ, La Primera Guerra Mundial..., pp. $41-87$.
} 
(minas de wolfranio y zinc en Noya, Galicia), minas andaluzas como Rio Tinto, Peñarroya Co. o Venta de Baños, el Ferrocarril del Norte, The British Westinghouse Electric \& Manufacturing Co., diversos bancos, como Barclays Co. y Lloyd Bank, armadores de barcos... ${ }^{16}$ Además, en el campo económico, los agentes británicos se ocuparon de crear un clima favorable a la firma de un tratado de comercio en los términos que interesaba a su gobierno, procurando "crear una comunidad de intereses industriales, comerciales y financieros entre Gran Bretaña y España" ${ }^{17}$. Negociaron, así, para obtener los productos que les interesaba, recursos mineros, o maquinaria eléctrica. Trataron sobre temas de construcción, venta de barcos, transportes y comunicaciones. Trabajaron para crear un banco industrial británico en España, o para trasladar oro británico al Banco de España ${ }^{18}$. De tal forma, conseguir una ventajosa situación dentro de la economía española y de las inversiones que requería la modernización del país sería un objetivo señalado en la guerra, pero que se prolongaría más allá de la contienda.

En tercer lugar, era necesario beneficiarse de la estratégica situación española, y más aún cuando arreció la guerra submarina. En ese sentido, era necesario proteger las rutas de comunicación con Gran Bretaña, así como asegurar el abastecimiento y auxilio de los barcos y submarinos aliados. De igual manera, había que conocer, dificultar y si era posible impedir las actuaciones del enemigo en la Península, especialmente en el campo de las comunicaciones, la obtención de recursos y la guerra submarina. Al tiempo se debía evitar la venta y transporte de mercancías españolas a los países centroeuropeos.

\section{4. ¿Cómo ATRAER a ESPAÑA AL BANDO ALIADO? AgENTES BRITÁNICOS EN ESPAÑA}

A fin de conseguir los objetivos deseados, Gran Bretaña desplegó en España una compleja red de agentes compuesta por los diplomáticos y el personal trabajando en la embajada, los agregados militares y navales, los responsables de oficinas comerciales, de prensa, propaganda y contrapropaganda o de pasaportes, la red de consulados y viceconsulados, especialistas con fines concretos y definidos enviados por diferentes ministerios y un potente servicio de espionaje y contraespionaje. Este último estuvo controlado desde Gibraltar por el mayor de Infantería Ligera de Marina Charles J. Thoroton, a las órdenes directas del Admiralty War Staff, aunque acabó por extenderse por todo el territorio español y por tener incluso delegados dentro de la embajada y de los consulados realizando múltiples labores ${ }^{19}$. Los servicios secretos colaboraron a veces con los diplomáticos, a quienes pidieron apoyo para determinadas misiones o

16 TNA, FO 1011/278; FO 1011/117; Cámara de Comercio de Barcelona, Caja 1032, Asuntos diversos sobre exportación y problemas derivados de la guerra, 1915-1918, negociaciones en torno al plomo, albayalde, carbón, hierro, estaño, aluminio, sulfato de aluminio, sulfato de cobre, antimonio, aceite de anilina, cloruro de sosa, clorato de sosa, algodón, lana, madera, textiles, mantas, pieles, cuero, calzado, material eléctrico, maquinaria, locomotoras, productos para la construcción, maderas, cáñamo, yute, vino, patatas, frutas, aceite, harina, drogas y productos químicos...

${ }^{17}$ TNA, FO 1011/117, Carta de Loraine a Hambro, 29 de abril de 1918.

${ }^{18}$ TNA, FO 371/3034, 17 de julio de 1918.

${ }^{19}$ El papel de Thoroton al frente de los servicios secretos británicos desplegados en España está explicado en el excelente trabajo de C. GARCÍA SANZ, La Primera Guerra Mundial..., pp. 199-285. Dentro de trabajo más globales, también en F. GARCÍA SANZ, España en la Gran Guerra..., pp. 67-68 y 89-95 y Keith JEFFERY, M16. The History of the Secret Intelligence Service, 1909-1949, London, Bloomsbury Publising, 2011, pp.91-94. Desde una perspectiva familiar, basada en los papeles conservados por sus descendientes, es interesante el trabajo de Philip VICKERS, Finding Thoroton. The Royal Marine who ran British Naval Intelligence in the Western Mediterranean World War One, Eastney, Royal Marines Historical Society, 2013. 
para que realizaran tareas que ellos no podían llevar a cabo de forma oficial ${ }^{20}$. Teóricamente, la legación de Madrid actuaba como intermediaria entre esos servicios, el cuerpo consular y las autoridades españolas, pero las relaciones entre las distintas instancias no siempre fueron fáciles, ni estuvieron claras, por problemas de jerarquía y competencias. En cualquier caso, diplomáticos, militares, representantes de distintas instituciones, civiles, espías, profesionales y aficionados se unieron al fin en el común objetivo de ganar la guerra para Gran Bretaña, también en la Península y en sus islas adyacentes.

Entre esa amplia y compleja red, en este trabajo se van a seguir las opiniones, actuaciones y documentación generada por tres personajes que nos han resultado especialmente interesantes. En primer lugar, el embajador británico en Madrid, Sir Arthur H. Hardinge. Era un diplomático preparado, inteligente y sensato. Buen observador, fino analista, capaz de emitir juicios certeros, jugosos y llenos de matices. Durante la guerra, mantuvo una correspondencia fluida y directa con el primer ministro, el secretario y el subsecretario de Estado para Asuntos Exteriores y altos funcionarios de otros ministerios ${ }^{21}$. Oficialmente, de Hardinge dependían jerárquicamente el personal diplomático, los cónsules, los agregados militar, naval, comercial y de propaganda, así como muchos de los enviados para misiones especiales, que al llegar a la Península pasaban a depender del Foreign Office. Todos ellos debían enviar sus despachos y tramitar sus actividades a través del embajador, a pesar de que también tuvieran una relación directa con sus superiores en Gran Bretaña para asuntos específicos de su ramo -asuntos de los cuales, en teoría, debían informar al jefe de misión-. El embajador centralizaba así buena parte de los informes del personal británico, informes a los que no sólo daba cauce, sino que valoraba, comentaba, completaba o corregía y que son una fuente fundamental para entender la consideración británica de España durante la gran guerra. En sus permisos Hardinge era sustituido por el consejero de la embajada, JCT. Vaughan, quien estuvo al frente de la delegación española en algún momento clave de la contienda, como fue parte de la primavera de 1917.

En segundo lugar, el primer secretario de la embajada, Sir Percy Loraine. Barón de Kirkharle e hijo del almirante Sir Lambton Loraine, fue educado en Eton y Oxford, luchó en la guerra de los Boers en 1901 y entró en el servicio diplomático en 1904. Estuvo destinado en Constantinopla, Persia, Italia, China y Francia,

\footnotetext{
${ }^{20}$ TNA, FO 1117/278, Carta de Thoroton a Loraine, 26 de septiembre de 1916. La misión de Thoroton era, según explicaba él mismo en correspondencia secreta con Percy Loraine, con quien no tuvo una fácil relación, ocuparse de la venta de barcos, de los movimientos de sospechosos y agentes enemigos, y de la elaboración de una "black list". Sin embargo, más allá de lo expuesto, se ocupó de tareas mucho más amplias a fin de garantizar los intereses británicos durante la guerra y contrarrestar las acciones de los países centroeuropeos en España, creando una completa red de agentes por la Península y sus archipiélagos, tal como han explicado los autores citados en la nota anterior.

${ }^{21}$ Los primeros ministros británicos durante la Primera Guerra Mundial fueron: Herbert H. Asquith, $1908-1916$ y David Lloyd George, 1916-1922. Los secretarios de Estado para Asuntos Exteriores fueron Sir Edward Grey, diciembre 1905-diciembre 1916, Arthur James Balfour, diciembre 1916-julio 1918, y Lord Robert Cecil, julio 1918-octubre 1919 (Assistant Secretary of State for Foreign Affairs hasta enero de 1919). Los subsecretarios de Estado fueron Sir Arthur Nicolson, noviembre 1910-junio 1916 y Lord Hardinge of Penshurst, junio 1916-noviembre 1920.

A su vez, los gobiernos españoles, mucho más inestables, estuvieron presididos por Eduardo Dato, del 27 de octubre de 1913 al 9 de diciembre de 1915; por el conde Romanones del 9 de diciembre de 1915 al 19 de abril de 1917; por Manuel García Prieto del 19 de abril al 11 de junio de 1917; de nuevo por Eduardo Dato del 11 de junio al 3 de noviembre de 1917; otra vez por García Prieto del 3 de noviembre de 1917 al 22 de marzo de 1918; y por Antonio Maura del 22 de marzo al 9 de noviembre de 1918.
} 
antes de ser enviado a Madrid en $1916^{22}$. Era un hombre muy bien relacionado y un magnífico jugador de polo que entendía mucho de caballos, por lo que se introdujo fácilmente en el círculo de las amistades del Alfonso XIII y en la alta sociedad española. Loraine colaboraba estrechamente con el embajador en las tareas diplomáticas que le eran encomendadas, pero al tiempo enviaba informes, en forma de cartas privadas y secretas, al jefe de Inteligencia del Admiralty War Staff, Lord Herschell, y mantuvo correspondencia regular durante la guerra con $\mathrm{C}$. Eric Hambro, responsable de propaganda en el ministerio de Información, los cuales a su vez le encargaron distintas misiones. Quizás por ello, en sus papeles del Foreign Office se explica textualmente que "durante la Primera Guerra Mundial estuvo comprometido con los servicios de inteligencia del Admiralty War Staff", aunque no sabemos si fue de manera oficial u oficiosa $^{23}$.

Del papel de Loraine nos dan cuenta también las valoraciones que de él hicieron sus superiores en Gran Bretaña, que hablaron de la utilidad de sus opiniones ${ }^{24}$, de cómo sus consejos eran seguidos por otras personas del servicio, aún sin que ellas supieran de dónde emanaban esas directrices ${ }^{25}$, del interés del D.I.D. por sus conversaciones con el rey y otros políticos españoles ${ }^{26}$, de trazar una estrategia para que casualmente pudiera encontrarse con el monarca en los campos de polo o en las carreras a fin de informarse extraoficialmente de sus opiniones en cuestiones que interesaba conocer o de trasladarle otras que quisieran que conociera ${ }^{27}$. A veces le solicitaron que trabajara para conseguir un crédito en España, que no fluctuase excesivamente la libra, que explorara la posibilidad de crear un banco industrial bajo control británico $u$ otros arreglos financieros ${ }^{28}$; le explicaron también cómo debía relacionarse con Thoroton, responsable de los servicios secretos en Gibraltar o tantas otras tareas delicadas que lord

\footnotetext{
${ }^{22}$ Gordon WATERFIELD, Professional Diplomat: Sir Percy Loraine of Kirkharle between 1880 and 1961. London, John Murray, 1973.

${ }^{23}$ TNA, FO 1011, "Loraine Papers". En la primera página de este legajo figura una biografía de este diplomático, en la cual se lee textualmente: "During the First World War he was engaged in intelligence work for the Admiralty War Staff, except for a period following his father's death in May 1917, when he returned home to settled his affairs". A pesar de ello, como han puesto de relevancia Carolina García Sanz y Fernando García Sanz en sus trabajos sobre el servicio secreto británico en España, en anteriores artículos (ver nota 1) imputé a Percy Loraine más atribuciones en los servicios de inteligencia de los que realmente ejerció.
}

${ }^{24}$ TNA, FO 1011/117, Carta de Hambro a Loraine 10 de junio de 1918: “Among all the letters, memoranda and discussions I have had of all kinds with people qualified-or unqualified- to speak of the matter, yours is the only one that has given me practical suggestions".

${ }^{25}$ Ibídem: "Instructing Walter, I have told him to cat a great deal on your suggestions, though I have not informed him that they emanate from you".

${ }^{26}$ TNA, FO 1011/278, Admiralty Intelligence Division, Private and Secret, Carta de Herschell a Loraine, 8 julio 1917 : "The D.I.D. is much obliged to you for the excellent use you made in your conversation with the King of the submarine question. That is the line to take".

${ }^{27}$ Ibídem: En la carta Hershell señala a Loraine "the necessity, if you can possibly manage it, of your playing polo at Santander and other places in the North in order to meet the King. You seem to have got on such an excellent footing with him that I am sure it is worth some sacrifices".

${ }^{28}$ TNA, FO 1011/117, Carta de Hambro a Loraine, 14 de marzo de 1918. 
Herschell y Hambro le solicitaron que realizara ${ }^{29}$. En alguna ocasión le mencionaron incluso la tranquilidad que les daba que estuviera en España controlando las acciones que habían encargado a otras personas ${ }^{30}, 0$ le solicitaron que articulara cauces artificiales para que les llegaran oficialmente papeles que ya obraban en su poder porque Loraine se los había enviado de forma personal, pero de los que no les era posible hablar, ni utilizar, porque teóricamente no debían conocerlos ${ }^{31}$; indicaron también el papel protagonista de Loraine en alguna misión importante, como en la salida del comandante del U.C.56, aunque los créditos no fueran para él, lo cual parece indicar que Loraine realizaba misiones confidenciales para ellos ${ }^{32}$.

En tercer lugar, en el organigrama británico en España también ocupó una posición muy destacada Josceline C. H. Grant, comandante del Ejército y agregado militar en Madrid de 1916 a $1919^{33}$. Dependía jerárquicamente del embajador, con quien colaboró en muchas ocasiones, pero además enviaba correspondencia confidencial al Colonel B.T. Buckley de la War Office, y se comunicaba también con el Department of Military Intelligence ${ }^{34}$. Mantuvo una frecuente relación con el monarca, con el que departía en largas conversaciones confidenciales. Estaba bien relacionado con el mundo político, con círculos económicos y con la prensa. Tenía informantes en el Ejército y en el entorno del rey. No sólo se ocupaba de asuntos militares, sino también de cuestiones de política, economía y comercio, estrategia y comunicaciones, o propaganda y contra-propaganda. Sus propios informes reflejan bien cuál fue su papel dentro del esfuerzo bélico de los británicos en España. De ellos se deduce que el agregado militar desempeñaba misiones delicadas más allá de las que el embajador podía llevar a cabo como diplomático: "La actitud de nuestro embajador es que no debemos mostrar nuestra ansiedad en el asunto porque los españoles aprovecharían para obtener mejores condiciones en los intercambios. Pero yo creo que debemos ir más allá y presionarles para obtener lo que queremos. El embajador no puede hacerlo por los cauces oficiales, pero yo puedo maniobrar extraoficialmente"... "Le escribo una carta personal y confidencial porque sé que así solo usted y el D.I.M. la leerán y sabrán lo que he dicho sobre el embajador... Yo actúo bajo y junto al embajador, y no debo tomar ningún paso sin su conocimiento y consentimiento. Pero como ya le he dicho, creo que va a ser necesario que enseñemos los dientes, y yo puedo ir a ver al rey

\footnotetext{
${ }^{29}$ TNA, FO 1011/278, Admiralty Intelligence Division, Private and Secret, Carta de Herschell a Loraine, 3 de agosto de 1917; Carta de E.F. Davies a Loraine, 30 de junio de 1917; TNA, FO 1011/117, Carta de Hambro a Loraine, 14 de marzo de 1918.

${ }^{30}$ TNA, FO 1011/278, Carta de Herschell a Loraine, 6 de diciembre de 2016.

${ }^{31}$ TNA, FO 1011/278, Carta de Herschell a Loraine, 9 de agosto de1918: "As, however, we are not likely to see this memorandum and as I hardly like to ask for it, could you not perhaps give it to John Harvey, who is Naval Attaché and is presumably interested in remarks concerning the D.N.I.'s service? This seems rather a round-about fashion, but if, for once, we can get hold of something, other than complains, regarding the service, which we could keep for possible further use, we should be very glad to have it!"

32 Ibídem: "We were all delighted at your success in getting the Commander of the U.C. 56 removed, though it was a little hard that Filson Young and the "Times" should have nobbled all the credit there!"

${ }^{33}$ Anteriormente este puesto fue desempeñado por el Col. Hon. Henry Yarde-Buller, que fue agregado militar para Francia, España y Portugal de 1914 a 1916.

${ }^{34}$ TNA, WO 106/5128.
} 
informalmente de una manera que el embajador no puede. Yo puedo moverme por debajo suyo en esferas y asuntos en los cuales él, oficialmente, no puede actuar" ${ }^{135}$.

El papel de Grant fue, además, especialmente relevante porque en los primeros años de la guerra no hubo un agregado naval en Madrid ${ }^{36}$, por lo que, tal como estaba previsto en la legislación británica, el agregado militar asumió oficialmente sus funciones, aunque desde Gibraltar Thoroton se ocupara de otros muchos asuntos. En el otoño de 1917, a la vista de las dimensiones que estaba adquiriendo la guerra submarina y marítima en aguas españolas y de las continuas actividades alemanas en las costas españolas, los estados mayores aliados comprendieron que era vital una mayor coordinación de sus servicios y un esfuerzo conjunto de los agregados navales destacados en este país. Por ello solicitaron la presencia de un representante naval británico permanente en la capital de España, que pudiera informar de lo que ocurría en las aguas territoriales de este país y conjuntar sus actuaciones con la de los agregados navales de los demás países. En diciembre de 1917, se propuso para el puesto al capitán de navío John Harvey, que en ese momento servía en Gibraltar ${ }^{37}$, incorporándose a su nuevo puesto en Madrid en marzo de $1918^{38}$.

Por lo general, los representantes británicos tuvieron una cordial y frecuente relación con el rey. Las reuniones del embajador con el monarca entraban dentro del habitual y lógico desempeño de las labores diplomáticas. Las entrevistas con el agregado militar y luego con el agregado naval y otros cargos menores, tuvieron un carácter más extraordinario, aunque llegaron a convertirse en usuales y se desarrollaron en un clima de confianza, relativa sinceridad y mutua colaboración. Loraine se reunió frecuentemente con el monarca, a veces por cauces oficiales y otros muchos extraoficiales, aprovechando aficiones comunes. Todos ellos concedieron gran importancia a la figura del soberano, llegando a calificarle como "la persona más popular del país". Siempre subrayaron su peso político. Le consideraban una persona bien informada, aunque voluble, manipulable y de reacciones imprevistas. Decían de él que no era un árbitro imparcial, ajeno a los movimientos cotidianos, sino que tenía iniciativa y voz propia, lo cual los británicos no sabían si aplaudir o temer, pero en cualquier caso, decidieron tener muy en cuenta sus opiniones porque sabían que su voz era escuchada por los políticos y se tenía muy presente en las decisiones del gobierno. Por ello creyeron fundamental conocer los sentimientos y opiniones del rey, estar enterados de cuales iban a ser sus movimientos y saber sus reacciones ante lo que iba aconteciendo. Procuraron también influir en sus opiniones, inculcarle ideas favorables a la causa aliada y, sobre todo, contrarrestar las informaciones y las imágenes distorsionadas que los agentes alemanes vertían en su entorno.

La magnitud de personal británico trabajando en España durante la guerra y la amplitud de cometidos desempeñados puede dar idea de que la posición española en la contienda no era indiferente al gobierno de Londres, que no dejó de intentar nunca que se inclinaran a favor de los aliados y de sus propios intereses a pesar de la temprana declaración de neutralidad decidida por el gobierno español. Veámoslo

\footnotetext{
${ }^{35}$ TNA, WO 106/5128, Fragmentos de distintas cartas enviadas por Josceline CH. Grant al Colonel BT. Buckley, de la War Office.

${ }^{36}$ Anteriormente habían desempeñado el puesto de agregado naval para Francia, España y Portugal, en 1914, el Capt. William A.H. Kelly, en 1915, el Capt. Michael Henry Hodges, y en 1916, el Comm. Fitzmaurice Acton, todos ellos de la Royal Navy y sin un destino permanente en España.

${ }^{37}$ TNA, FO 371/3368, Under Secretary of the Admiralty to Under Secretary of State, 31 de diciembre de1917.

${ }^{38}$ TNA, FO 371/3368, Instrucciones del Admiralty al Acting Captain John Harvey, R.N, 1 de enero de1918.
} 
con mayor detenimiento a través de dos momentos decisivos para definir la posición española en la guerra: 1914 y 1917.

\section{1914: ANÁLISIS DE LAS POSIBILIDADES DE QUE ESPAÑA ENTRARA EN LA GUERRA}

Uno de los primeros asuntos que analizaron los británicos, nada más empezar el conflicto, se refirió a las posibilidades de que España entrara en la guerra, sopesando las ventajas e inconvenientes de tal circunstancia.

En los primeros días de guerra, Sir Edward Grey, secretario de Exteriores, escribió al almirante en jefe de la Marina para informarle de que podían contar con la actitud amistosa de España y de Portugal en la contienda. El gobierno portugués solo esperaba la invitación del gobierno Su Majestad para declararse aliado de Gran Bretaña. También era posible que el gobierno español se manifestara favorable al establecimiento de una alianza con Francia o Gran Bretaña, o con las dos juntas. Grey manifestaba así que tenía "todas las razones para suponer que las relaciones entre España y Portugal son las de dos estados que van a colaborar para asistir a sus aliados beligerantes" ${ }^{39}$.

En esa tesitura, el Almirantazgo consideró que sería positivo conseguir la colaboración no solo portuguesa, sino también la española: "la adición de España y Portugal a los aliados sería ventajosa para nosotros desde un punto de vista naval", subrayando que "nuestros compromisos navales no se verían incrementados por ello". El apoyo de estos dos países no supondría nuevos esfuerzos. Las obligaciones con Portugal ya estaban contraídas según los tratados de alianza vigentes $\mathrm{y}$, sin embargo, "en tanto mantuvieran el dominio del mar", el control de las islas portuguesas de Madeira, Cabo Verde y Azores ofrecería estratégicas bases de carboneo para los cruceros y mercantes británicos, evitando además que los barcos enemigos pudieran utilizarlas o amenazarlas. Tampoco la adhesión de España implicaría responsabilidades extra: "su pequeña marina, con nuestro control del mar, podría prevenir que sus costas fueran atacadas y Canarias podría servir como otra útil base de carboneo". Por ello el Almirantazgo concluía que "la alianza con ambas potencias puede ser útil en todos los sentidos" 40.

También desde París el embajador francés confirmó la actitud favorable de España: "mi colega español me informa de que el Gobierno español ha dado seguridades al Gobierno francés de que pueden quitar las tropas de la frontera franco-española en la completa confianza de la actitud amigable de España hacia Francia en el conflicto con Alemania" ${ }^{41}$.

Sin embargo, frente a las optimistas impresiones expresadas en Londres y en París, desde las primeras semanas de guerra, el embajador británico en Madrid advirtió de que no se debía esperar una activa participación española en la guerra. A pesar de que buena parte de las simpatías del país estaban con los aliados, y de que tanto el rey como destacados políticos le habían hecho saber que respaldarían su causa y les ayudarían en lo posible, otras muchas personalidades abogaban por evitar el conflicto y la sociedad española en su conjunto parecía reacia a entrar en guerra y apoyaba mayoritariamente una posición de neutralidad.

\footnotetext{
${ }^{39}$ TNA, ADM 137/1029, Informe del Secretario de Estado al Secretario del Almirantazgo, 8 de agosto de 1914.

${ }^{40}$ TNA, ADM 137/1029, Informe Secreto del Almirantazgo al Foreign Office, 12 de agosto de 1914.

${ }^{41}$ TNA, ADM 137/1029, Despacho cifrado de Sir Bertie, embajador en París, a Sir E. Grey, enviado el 3 de agosto, recibido el 6 de agosto de 1914.
} 
Hardinge reconocía el apoyo del Alfonso XIII a la causa aliada: "El rey es, probablemente, uno de los pocos españoles que querría, si le fuera posible, intervenir al lado de la Triple Entente. Su Majestad me ha asegurado a mí, al igual que su ministro de Exteriores, que sus simpatías personales están con nosotros, aunque tiende a acusar a Rusia y a excusar a Austria en la cuestión serbia, el origen o el pretexto de la guerra según su opinión, y considera que el abandono de Italia de sus aliados es "a filthy act" (un acto inmundo), tal como lo dijo en inglés, el idioma en el que estaba hablando conmigo. El rey ha preguntado al embajador francés si ha oído algo sobre los alemanes y Fernando Po, y le ha manifestado que incluso si los alemanes prosiguen victoriosos y entran en París, los franceses no se deben rendir porque en ese caso les llegarán ayuda "from other quarters" (de otros lados)" 42.

A pesar de ello, el 31 de Agosto de 1914, pocos días después de que apareciera en el Diario Universal ("el diario del Conde de Romanones") el artículo "Neutralidades que matan", Sir Arthur H. Hardinge escribía a Sir Edward Grey insistiendo en las escasas posibilidades de que España entrara en el conflicto apoyando a los aliados. En carta confidencial, el embajador explicaba que el texto había sido inspirado, si no redactado, por el líder de los liberales en persona, con objeto de agradar al rey. En él se defendía que España no debía permanecer neutral, sino que debía aliarse con las fuerzas de la Triple Entente a fin de estar en condiciones de defender la integridad de su territorio y evitar que las Baleares, las Canarias y las costas de Galicia quedaran indefensas. Con ello se podrían mantener también las esperanzas de expansión en Marruecos, frente a la pretensión alemana de ocupar la costa del Norte de África desde Trípoli a Fernando Po, y se conseguiría que si ganaban los aliados, tal como se esperaba, contaran con España a la hora de recomponer el mapa europeo y sus áreas de influencia. Por ello, subrayaba el embajador, en el artículo se defendía que era una hora decisiva en la cual España debía optar por la intervención al lado de quien más podía beneficiarles, los aliados.

No obstante, a pesar de las razones esgrimidas en ese artículo, Hardinge era poco optimista respecto a los efectos del texto: " No creo que esos argumentos tengan mucho efecto sobre la opinión pública. La gran mayoría de los españoles simpatiza con los oponentes de Alemania, especialmente después del brutal tratamiento a Bélgica. La única excepción son los carlistas, que rechazan a la república francesa por infiel y que esperan que una victoria alemana pueda conllevar la caída de los Borbones, el trono para D. Carlos y la devolución de Gibraltar a España. Pero incluso los carlistas son conscientes de que la situación económica, militar y geográfica de España en Europa y en África impide una alianza con Alemania, y por ello se unen a la gran mayoría de personas moderadas que consideran que para España lo mejor sería permanecer neutrales. Los socialistas y los republicanos, a pesar de sus simpatías por Francia, se oponen fuertemente a una intervención activa en su favor". Concluía así subrayando que "mientras el señor Dato permanezca en su puesto, a no ser que se produzca una grave violación de la neutralidad española por los alemanes, o a no ser que Italia la rompa con sus partisanos, el gobierno conservador español no se moverá de su actual posición de prudencia" ${ }^{43}$.

Días después, en una nueva misiva, el embajador británico comentaba otro artículo publicado por Romanones, esta vez en El Imparcial. En él Romanones manifestaba que "dada la trayectoria diplomática de España en los últimos años, y muy especialmente después de 1907, no podía olvidarse que los intereses políticos, económicos y estratégicos españoles se inclinaban en favor de los aliados" y que "la colaboración

\footnotetext{
42 TNA, ADM 137/1029, Carta de Sir Hardinge a Sir Edward Grey, 31 de Agosto de 1914, no 149, Confidential.

${ }^{43}$ TNA, ADM 137/1029, Carta de Sir Harding a Sir Edward Grey, 31 de Agosto de 1914, no 149, Confidential.
} 
con Gran Bretaña se había demostrado fundamental para España", por lo que, incluso en el caso de que permanecieran neutrales no debían olvidar esas premisas. Neutralidad no significaba aislamiento. El mensaje era claro, pero Hardinge puntualizaba que tales declaraciones podían suponer que España mantendría una actitud favorable hacia los británicos, pero nada más. Romanones, a quienes los británicos tenían gran consideración, no tenía fuerza suficiente para imponer tal opción ${ }^{44}$. García Prieto y Maura habían declarado que rechazaban cualquier política de aventuras tanto en el bando aliado como en el contrario. Melquiades Álvarez, a pesar de la pública preferencia de los reformistas o republicanos moderados por los aliados occidentales, había manifestado que se debía hacer todo lo posible para permanecer neutral. La única excepción a esta postura unánime era la de Lerroux, líder del partido radical, que había comenzado una cruzada para apoyar a la república francesa, señalando al rey como partidario de esa política y advirtiendo a sus seguidores de que una Alemania victoriosa significaría un nuevo Gibraltar en las Baleares. No obstante, indicaba el embajador, sus esfuerzos no encontraban respuesta en la opinión pública, mientras que el gobierno estaba recibiendo solicitudes para que se mantuviera la neutralidad. Por otra parte, Hardinge señalaba que la prensa carlista y jesuita, firmes partidarios de Alemania, miraban al emperador alemán como un héroe de la cristiandad que se había levantado contra la inmoral e infiel Francia, y desde el consulado alemán en Barcelona se anunciaban diarias derrotas de los aliados.

En su análisis Hardinge subrayaba de nuevo que "el rey, sin duda, estaría dispuesto a intervenir de nuestro lado, tal como le ha indicado al embajador francés (a mí solo me ha hablado de su simpatía personal por nuestra causa), pero su majestad no tiene la fuerza suficiente para enfrentarse a la determinada oposición de su gabinete, al que sabe apoyado por los principales líderes del parlamento. En esa línea, el embajador, que había dedicado muchas gestiones y muchos informes a analizar la cuestión, concluía que era "absolutamente obvio que una opinión pública que no toleraría una lista de bajas en sus protectorados africanos y que protestaría por una guerra en la costa marroquí, muy difícilmente daría la bienvenida a la carnicería y a la pesada carga que supondría un conflicto europeo" ${ }^{45}$.

Los británicos comprendieron, por tanto, en el verano de 1914, que sería difícil contar con la colaboración española como aliado activo en la guerra. Sin embargo, consideraron posible conseguir una actitud amistosa y favorable a sus intereses. Esa era la situación desde la que se debía trabajar.

\section{CONTRA LA UTILIZACIÓN ALEMANA DE ESTACIONES DE RADIO ESPAÑOLAS}

Una vez conocida la posición de neutralidad que iba a adoptar España, una nueva preocupación de los británicos en 1914 fue que las potencias centrales no encontraran allí colaboración alguna. En ese sentido, se movilizaron a fin de evitar el uso de estaciones de radio españolas para las comunicaciones alemanas.

El 4 de agosto de 1914, el buque Telconia saboteó los cables transatlánticos alemanes a Vigo y Tenerife en lo que se consideró el primer acto ofensivo de Gran Bretaña en la contienda ${ }^{46}$. Aún así no fue

\footnotetext{
${ }^{44}$ Le calificaban, así, como "el hombre de Estado más importante de este país"TNA, FO 371/3033, Vaughan a F.O., 19 de Abril de 1917, indicando que en "en términos generales ha llevado una política decididamente de nuestro lado", TNA, FO 371/3033, Carta muy confidencial de Hardinge al FO, 20 de enero de 1917.

${ }^{45}$ TNA, ADM 137/1029, Carta de Sir Hardinge a Sir Edward Grey, 14 de septiembre de 1914, no 156, Confidential.

${ }^{46}$ GONZÁLEZ CALLEJA y AUBERT, Nidos de espías..., pp. 136-137.
} 
suficiente. En septiembre de 1914, los servicios británicos alertaron de que desde estaciones de radio españolas se estaban recibiendo y enviando mensajes alemanes, muchos de ellos cifrados. Una vez cortado el cable que unía a Alemania con sus colonias africanas, los escuchas británicos detectaron que las comunicaciones de las estaciones alemanas de Norddeich y Nauen con América, África y Canarias se estaban realizando a través de la estación militar de Carabanchel: el tráfico diario entre Madrid y Berlín había aumentado hasta una cantidad cercana a los 1.000 grupos de cifrados, que era mucho más de lo que la propia Foreign Office originaba cada día. El informe británico subrayaba que el uso de las estaciones de radio españolas neutralizaba los legítimos esfuerzos británicos por aislar a Alemania. Proporcionaba también a los alemanes un medio de comunicación con sus barcos en el Atlántico. De hecho, habían detectado mensajes directos entre estaciones en Canarias y barcos alemanes y sabían que los mensajes de radio entre Tenerife y Cádiz estaban controlados por el cónsul alemán. Por ello advertían que los alemanes habían encontrado en las estaciones de radio españolas "un instrumento listo para ser usado, promovido por ellos mismos en tiempos de paz, y en el que todo señala hacia el hecho de que el personal militar que lo maneja está profundamente implicado con los directores y managers de la compañía alemana de radio, The German Wirelesss Company"47.

Tras recibir la protesta británica, el ministro de Exteriores español contestó que sólo se permitía el uso de la estación de Carabanchel para asuntos diplomáticos oficiales y sin cifrar. Únicamente se autorizaban las trasmisiones del propio gobierno español con su embajada en Berlín, que antes se hacían vía Francia, así como las comunicaciones oficiales entre el gobierno alemán y su embajada en Madrid, las cuales previamente se realizaban a través de Austria, Francia y Barcelona, encontrándose entonces cerrados ambos caminos, con los consiguientes perjuicios políticos y económicos. Apoyaban la legalidad de tal proceder en el artículo 8 de la 5a Convección de la Conferencia de la Haya de 1907, que regía los derechos y deberes de los países neutrales durante una guerra. En esa tesitura, el gobierno español ofreció que también Gran Bretaña pudiera utilizar esa estación militar para asuntos oficiales, en vista de la interrupción temporal de sus comunicaciones de cable a través de la vía habitual de Bilbao. En cualquier caso, si los británicos podían probar que los alemanes habían abusado de su privilegio, éste sería aún más restringido o incluso anulado, y en ese sentido Lema subrayaba que la petición del embajador alemán para utilizar esa estación de radio a fin de enviar mensajes a Tenerife y a Lisboa había sido denegada ${ }^{48}$.

A pesar de esa amistosa disposición, el gobierno británico reiteró sus quejas, considerando el asunto favorecía a un país beligerante en serio perjuicio de otros. Afirmaba que ello estaba favoreciendo el movimiento de los barcos de las potencias centrales en el Atlántico y posibilitaba las operaciones contra buques británicos. El ministro de Exteriores español comentó entonces al embajador británico en Madrid que a su gobierno le dolía la queja inglesa en la que le acusaba de favorecer a Alemania en detrimento de Gran Bretaña porque estaba verazmente probado que España había deformado muchas veces la neutralidad en favor de los aliados, una situación que el propio Hardinge reconocía en su correspondencia con Grey: "El ministro añadió que España, verdaderamente, había forzado la neutralidad en muchos aspectos en beneficio de los aliados" ${ }^{\prime 9}$. Nuevamente los británicos insistían, pues, en la idea de una neutralidad benévola por parte española.

\footnotetext{
47 TNA, ADM 137/1029, Secret, "Spain and Wireless Telegraphy", Informe a máquina sin firma.

${ }^{48}$ TNA, ADM 137/1029, Carta de Lema al embajador británico en Madrid, 25 de septiembre de 1914.

${ }^{49}$ TNA, ADM 137/1029, Carta de Hardinge a Grey, 2 de octubre 1914 y Carta de Grey al ministro de Asuntos Exteriores
} 
Aún así, las quejas de Grey recibieron por respuesta una dura misiva por parte del embajador español en Londres, Merry del Val: "Voy a refrenar por el momento discutir en detalle el caso formulado por su Excelencia, así como a expresar mi opinión personal sobre la materia, más aún cuando estoy obligado a coincidir con la posición que adopte mi gobierno"..."Su Excelencia parece sorprenderse de que los oficiales alemanes y austriacos en las Canarias hayan sido autorizados a trasmitir por radio mensajes cifrados a sus respectivas embajadas en Madrid. En este punto debo señalarle que el Cónsul de Su Británica Majestad en el archipiélago ha estado enviando hasta fecha muy reciente telegramas de radio cifrados a barcos británicos, así como recibiendo otros, con el resultado de que mi Gobierno se vio obligado a prohibir ese tipo de correspondencia, lo cual hizo, no para perjudicar al Gobierno británico, sino movido por las recientes quejas presentadas por Sir Arthur Hardinge protestando por esa facilidad y reclamando que se prohibieran tales comunicaciones con los barcos de guerra y mercantes de las todos los países extranjeros"... "Su Excelencia acierta plenamente en atribuir a mi Gobierno la firme intención de cumplir estrictamente con los deberes de la neutralidad. De igual forma, puede estar seguro que sus peticiones encontrarán en Madrid el mismo espíritu de marcada cordialidad que ha mostrado de mil formas tangibles desde el comienzo de la guerra. Puede confiar también en que sus apreciaciones respecto al uso de cables serán tenidas en consideración, pero también tengo que decirle que encontraría una recepción más favorable de mi Gobierno si, a la vista de los medios de comunicación existentes, los oficiales británicos hubieran actuado hasta la fecha de forma más acorde con los sentimientos de mi Gobierno. Es una lástima que el comercio español esté ahora sufriendo un grave perjuicio por la manera en que el censor británico ha interpretado sus deberes interrumpiendo casi completamente nuestras relaciones comerciales con los Estados Unidos y deteniendo mensajes de contenido puramente comercial...Me parece que el cese de procedimientos tan vejatorios que son totalmente perjudiciales para el comercio español serían el mejor camino para predisponer a mi Gobierno a una solución que fuera aceptable a todas las partes en la cuestión del uso de las comunicaciones sin cable" ${ }^{\prime 50}$.

A pesar de las facilidades dadas por los españoles y dado que no pudo obtener lo que deseaba, que era que los alemanes no pudieran seguir usando esa estación de radio, el juicio final de los británicos a este asunto no pudo ser más duro: "Este es el estado de la cuestión en España en este momento, una situación que solo es equiparable a la de las pequeñas repúblicas de América Central, donde por lo menos los gobiernos tienen la excusa de que no son lo suficientemente poderosos para mantener su neutralidad" ${ }^{51}$. En cualquier caso, la cuestión de la utilización alemana de las estaciones españolas se mantuvo abierta a lo largo de la guerra, y todavía en 1917 y 1918 británicos y españoles seguían discutiendo en torno al asunto $^{52}$.

\footnotetext{
español, 13 de noviembre de 1914.

${ }^{50}$ TNA, ADM 137/1029, Alfonso Merry del Val a Sir Grey, 14 de diciembre de 1914.

${ }^{51}$ TNA, ADM 137/1029, Secret, "Spain and Wireless Telegraphy", Informe a máquina sin firma.

${ }^{52}$ GONZÁLEZ CALLEJA y AUBERT, Nidos de espías..., pp. 168-171.
} 


\section{1917: HUELGAS, REVOLUCIONES Y REGIONALISMOS FRENTE A LA REDEFINICIÓN DE LOS INTERESES BRITÁNICOS}

El segundo momento en que nos vamos a detener para evaluar la consideración británica de España y su posible interés en una mayor participación española en la guerra es en 1917, un período especialmente convulso tanto para la evolución de la guerra como para la situación interna española. A los representantes británicos en España les preocuparon los avatares ocurridos en aquel año marcado por complejos acontecimientos: las huelgas, revueltas y alteraciones al orden podían afectar muy negativamente a sus intereses: -las minas no debían pararse, los transportes no podían interrumpirse, los puertos no tenían que bloquearse, decían los ingleses- ${ }^{53}$.

A su vez, la formación de las Juntas de Defensa les llevó a cuestionarse el malestar de los militares, el estado del Ejército español, su excesiva imbricación en la política española y los sentimientos de desafección al rey existentes entre algunos de sus oficiales. Así, en junio de 1917, Hardinge informaba a Lord Cecil sobre las juntas revolucionarias: "Me temo que sin duda ciertos elementos de las Juntas Militares son desafectos al rey...el entorno del rey, es impopular entre el ejército, y la afición del rey al polo y al tiro de pichón es muy criticada por ser deportes ajenos a los españoles y en los que sólo los muy ricos pueden participar. Una satisfacción es el repudio de la gran mayoría de los oficiales del republicanismo y de los agitadores republicanos que están intentando pescar en aguas turbulentas, y entre ellos el señor Leroux, uno de los más capaces y peligrosos de todos ellos, muy activo en Barcelona" ${ }^{54}$. Hardinge consideró que el nuevo gobierno de García Prieto no era consciente del malestar del Ejército ni tenía capacidad para dar una respuesta firme: "Ese partido fue incapaz de notar el descontento que estaban creando en el Ejército la interferencia de su Majestad en la adjudicación de puestos militares y la influencia de la camarilla de Palacio" ${ }^{\prime 25}$... "La súbita insubordinación del Ejército ha introducido un nuevo elemento de peligro e incertidumbre en la política española que el Marqués de Alhucemas es incapaz de manejar con eficacia, representando a un pequeño grupo liberal, en vez de a un círculo de opinión fuerte y poderoso. Es un hombre débil en una crisis fuerte" ${ }^{56}$. A su vez, Grant informó al embajador de que existían "muchos rumores de todo tipo, uno de los cuales afirma que el Ejército ha amenazado con deponer al rey si no los respalda en sus demandas de reforma. Parece que el argumento es débil, porque tanto en $L a$ Correspondencia Militar como en Ejército y Armada aparecen indignados artículos que lo niegan y proclaman su lealtad al rey. Sin embargo, existe un indudable sentimiento de resentimiento contra el "partido de la corte (the Court party)" que rodea al rey" ${ }^{25}$.

Temieron también que la crisis de Cataluña pudiera comprometer la armonía general, al ser España un país profundamente regionalista, en el cual no se habían conseguido solucionar el problema de las provincias: "España es el país más regionalista del mundo, al igual que Francia es el menos... En España, los viejos sentimientos provinciales nunca han muerto... y en los últimos tiempos han demostrado una notable recuperación, sobre todo en Cataluña, la más avanzada y la menor de las provincias españolas. Hay que

\footnotetext{
${ }^{53}$ TNA, FO 371/3033, Informe de Grant, 3 de julio de 1917.

${ }^{54}$ TNA, FO 371/3033, Carta de Hardinge a Lord Robert Cecil, 10 de junio de de 1917.

${ }^{55}$ TNA, FO 371/3033, Carta de Sir A. Hardinge a Lord Robert Cecil, 12 de junio de 1917.

${ }^{56}$ TNA, FO 371/3033, Carta de Hardinge a Lord Robert Cecil, 11 de junio de 1917.

${ }^{57}$ TNA, FO 371/3033, Informe de Grant a Hardinge sobre las Juntas de Defensa, 10 de junio de 1917.
} 
recordar que hace un año o más, esta política culminó con el esfuerzo y el intento de mantener lo que se llama un parlamento no oficial en Barcelona, que además de las reformas políticas en otros asuntos exigió la autonomía para Cataluña. Madrid y la mayor parte del mundo oficial y político, como siempre ha sido, y sin duda sigue, se opusieron a esta demanda. Sin embargo, hace ya un año los regionalistas se convirtieron en una fuerza a considerar... y el Gabinete de Alhucemas ... contenía dos candidatos propuestos por el señor Cambó, el líder regionalista, el señor Ventosa y el señor Rodes ... La independencia o la anexión a Francia son ideas que a veces se han manejado... No hay duda de que es un problema para el cual se debe encontrar una solución en un futuro próximo... Se dice que si Romanones hubiera asumido el cargo, hubiera anunciado que su programa era conceder autonomía a Cataluña, así como lograr un buen entendimiento con los aliados en el extranjero y una reforma constitucional en casa" ${ }^{58}$.

En esa tesitura, a los británicos les preocuparon que los ataques a la monarquía pusieran en peligro la estabilidad en España. El embajador alertó entonces de que "la actual crisis puede comprometer la monarquía española y con ella al único elemento de orden y estabilidad que permanece en este país y evita la anarquía y los golpes de sangre" ${ }^{\prime 59}$. También el agregado militar señaló la importancia de Alfonso XIII dentro de la escena política española: "Es importante darse cuenta de que el rey tiene una reputación entre sus súbditos de estar extremadamente bien informado, que sus opiniones sobre la situación de los beligerantes tienen gran peso en el Gabinete y son un factor muy influyente en las decisiones del Gobierno" 60 . En ese esquema, de los tres personajes que estamos resaltando, a Loraine le correspondió la tarea de mantenerse cerca del rey, escuchar sus impresiones y trasmitirle determinados mensajes, ratificándole en aquella coyuntura concreta el interés de su gobierno por apoyar las monarquías constitucionales $^{61}$

El año 1917 fue, además, un tiempo condicionado por la guerra submarina y el ataque a barcos aliados y españoles en aguas jurisdiccionales de España, lo cual planteó de nuevo la posibilidad de un mayor compromiso español con la causa de los aliados y una hipotética ruptura con Alemania. En enero de aquel año, Alemania declaró la guerra submarina sin restricciones, considerando las aguas que rodeaban Gran Bretaña, Francia, Italia y el mediterráneo oriental zonas de guerra donde no se permitiría ningún tráfico marítimo. Aunque España fuera ajena oficialmente al conflicto, la medida podía afectar gravemente a los movimientos de los barcos españoles y el tránsito en las costas de la Península y sus archipiélagos. Se escribieron entonces numerosos artículos sobre la conveniencia de una respuesta española ante el dictado alemán y se volvieron a escuchar argumentos a favor de entrar en la guerra apoyando al bando aliado. Estados Unidos rompió relaciones con Alemania y el 5 de abril entraron en la guerra. Se rumoreó también que varias repúblicas americanas iban a seguir su ejemplo. Días más tarde tuvo lugar el hundimiento del San Fulgencio, que causó un especial impacto en la opinión española, aumentando el clamor belicista contra Alemania.

58 TNA, FO 371/4358, Political Intelligence Department, Foreign Office, Spain, 6 de diciembre de 1918, Confidential.

${ }^{59}$ TNA, FO 371/3033, Carta de Sir A. Hardinge a Lord Robert Cecil, 12 de junio de 1917.

${ }^{60}$ TNA, FO 371, 3033, Grant a Foreign Office, 7 de mayo de 1917.

61 TNA, FO 1011/278, Carta de Loraine a Hershell. Memorándum de una entrevista mantenida con el rey, 20 de junio de 1917. 
En ese contexto, en 1917 los intereses británicos se centraron en varios objetivos. Primero, que Alemania no obtuviera en España facilidades de ningún tipo. Segundo, combatir la guerra de submarinos alemana: acabar con los ataques en o desde aguas españolas; que los españoles no les abastecieran, no les resguardaran, no les encubrieran. Tercero, firmar un acuerdo comercial que asegurara el abastecimiento de productos españoles necesarios para el esfuerzo bélico. Cuarto, utilizar los recursos mineros españoles. Y quinto, contribuir a que se mantuviera la estabilidad política en la Península. Para ello los británicos trabajaron en varias direcciones: una posible declaración de beligerancia por parte de España, o en su defecto, la ruptura de relaciones entre España y Alemania; la firma de un acuerdo comercial entre España y Gran Bretaña; y la elaboración de continuos análisis de la posición española, la postura del monarca y su influencia en el proceso de toma de decisiones ante los conflictos planteados en aquella larga primavera y verano de 1917, con objeto de determinar la mejor conducta a seguir para beneficiar a sus intereses y actuar en ese sentido.

\section{9. "El POtencial VAloR de EsPaña COMO aliado"}

En marzo de 1917, el Foreign Office elaboró un memorándum secreto, destinado al War Cabinet, en el cual evaluaba el valor que España podría tener como un potencial aliado ${ }^{62}$. Señalaba así que, desde un punto de vista político, casi la única ventaja que tendría sería que la incorporación al bando aliado del país "más católico del mundo" influiría en la actitud de los católicos en Europa y en Estados Unidos, y supondría un importante respaldo propagandístico en América Latina. Aún así era cuestionable el valor práctico que podría tener el apoyo de los católicos a la causa aliada. De mayor utilidad sería que España dejara de ayudar a Alemania de todas las formas posibles. De igual forma, también sería positivo que España se incorporara decididamente al comercio con los aliados y les abriera su mercado y potenciales campos de inversión, en los cuales Alemania todavía tenía un peso considerable. Sin embargo, una entrada de España en la guerra podría exigir compensaciones que era necesario evaluar y que se podrían referir a Tánger, Gibraltar y Portugal.

En relación a Tánger, los británicos señalaron que desde un punto de vista portuario sería mucho mejor que estuviera en manos francesas que españolas porque estaría "infinitamente mejor administrado y desarrollado". El comercio británico crecería de manera mucho más rápida y efectiva con los franceses. Sin embargo, para los interés globales de Gran Bretaña un Tánger francés sería la peor solución. A cambio, las desventajas de un Tánger español sería el "completo estancamiento del puerto, ineficacia, corrupción e insurrecciones nativas".

Se podría pensar entonces en intercambiar Gibraltar por Ceuta, pero la renuncia del peñón sería mal acogida en Gran Bretaña: "Probablemente no hay ningún lugar de la tierra fuera de las islas británicas que el pueblo británico valore tan altamente como Gibraltar... Para ellos Gibraltar representa a la vez la gloria del pasado, el poderío del presente y la seguridad del futuro". Para que a los británicos les compensara realmente esa operación, deberían conseguir también Melilla, que contaba con importantes minas de hierro: "Desde luego, no hay que contentarse con Ceuta y nada más. Melilla sería de utilidad para nosotros, no sólo como un puerto, sino sobre todo a causa del mineral de hierro que existe en el distrito circundante, lo cual podría ser muy valioso para nosotros en una guerra futura". Sin embargo, la necesaria

\footnotetext{
62 TNA, ADM1/8546/334, Gibraltar-Ceuta Committee, "Potential Value of Spain as an Ally", Memorandum by the Foreign Office, marzo de 1917 y "Notes on Gibraltar and Ceuta", Foreign Office, Secret, 25 de abril de 1917.
} 
ocupación de las colinas que rodeaban Ceuta sería contestada por Francia, que vería con recelo esta operación: "Las dificultades para negociar un intercambio son obviamente inmensas". No obstante, ese intercambio mejoraría mucho las relaciones con España, que siempre había deseado recuperar Gibraltar ${ }^{63}$.

Respecto a Portugal, los españoles habían solicitado informalmente "tener mano libre" en ese país. Ello no implicaría una anexión de Portugal, sino la firma de una alianza ibérica en la cual predominara la influencia española. Esto no iría totalmente en contra de los intereses británicos, pero dificultaría el control del "habitual caos reinante en la república portuguesa". No había olvidar tampoco que Portugal era el aliado más antiguo de Gran Bretaña, y dejar "mano libre" a España en aquel país podría abrir una indeseable brecha entre británicos y portugueses. Por otra parte, la imagen de los aliados en el mundo, que estaban luchando por los derechos de las pequeñas naciones, podría verse muy perjudicada si apoyaban que España afirmara su influencia en Portugal ${ }^{64}$.

Por ello, la conclusión de este informe del Foreign Office y de las notas anexas fue que lo más ventajoso para Gran Bretaña era que España permaneciera neutral. Sin embargo, los acontecimientos iban a imponer otro rumbo.

\section{EL PRECIO DE UNA POSIBLE RUPTURA ESPAÑOLA CON ALEMANIA}

Durante unas semanas de abril de 1917, a consecuencia de la guerra submarina que se estaba desarrollando en aguas españolas y ante los ataques a barcos españoles, el gobierno de Romanones consideró la posibilidad de tomar una actitud más combativa contra Alemania ${ }^{65}$. El consejero de la embajada británica en Madrid comunicó a su gobierno tal eventualidad: "La entrada en guerra de Estados Unidos y el respaldo que han manifestado las repúblicas latinoamericanas a la Gran República, en vez de seguir el ejemplo de neutralidad de la Madre Patria, está provocando muchas reflexiones en España. Empieza a plantearse el espectro del aislamiento. No hay duda de que Romanones se ha dado cuenta de que se debe elegir entre estar con los aliados o perder el rango de gran potencia" ${ }^{66}$.

Se sopesó entonces la posibilidad de que España se declarara beligerante o enviara una dura nota en la que se rompieran las relaciones diplomáticas con Alemania. El gobierno británico evaluó ambas eventualidades, considerándolas positivas para sus intereses. Se acabaría así con las facilidades que Alemania estaba encontrando en la Península para sus comunicaciones, su abastecimiento y la guerra submarina. También favorecería el desmantelamiento de la poderosa red de espionaje y propaganda que agentes alemanes desarrollaban desde España. Igualmente, sería favorable para las relaciones comerciales y los suministros de productos españoles. Por ello, el Foreign Office envió a la embajada en Madrid un mensaje muy claro: "El Gabinete de Guerra británico apoyaría fuertemente la entrada de España en la

\footnotetext{
${ }^{63}$ TNA, ADM/1/8546/334.

${ }^{64}$ TNA, ADM/1/8546/334

65 Durante la guerra, España perdió cerca de 170.000 toneladas de barcos, un quinto de su marina mercante: 152,387 toneladas fueron hundidas por submarinos, 16.104 lo fueron por minas: BAILEY, The policy of the United States..., p. 273. Otros datos en GONZÁLEZ CALLEJA y AUBERT, Nidos de espías..., p. 161.

${ }^{66}$ TNA, FO 371/3033, Vaughan a Foreign Office, 17 de abril de 1917.
} 
guerra al lado de la Entente. Si hay algo que pueda sugerir, excepto la cesión de Gibraltar, podríamos encarecer a España a dar tal paso ${ }^{67}$.

Poco después pareció, sin embargo, que el gobierno español vacilaba respecto a qué actitud adoptar, por lo que rápidamente se pensó qué se les podría ofrecer a fin de ganarles para la causa aliada: "Desde el último lunes, Romanones ha variado su actitud. Lo máximo que podemos esperar es una ruptura de relaciones con Alemania. Por lo menos, esto serviría para luchar contra el nido de propaganda, intrigas e insidias que se ha convertido España. Creo que una promesa definitiva de ingleses y franceses apoyando a España en sus reclamaciones respecto a Tánger la inclinaría a una ruptura de relaciones y daría a Romanones una buena baza para negociar. Sin embargo, el embajador alemán está amenazando a Romanones con que la adopción de una postura desfavorable a Alemania podría provocar el bombardeo de puertos españoles por submarinos" ${ }^{68}$.

A fin de apoyar su causa, los representantes británicos en la Península se entrevistaron entonces con el rey, con círculos políticos de muy distinto signo y con hombres de negocios, mostrándoles las ventajas políticas, económicas y estratégicas que podrían obtener si España se decidía a romper sus relaciones con Alemania o a entrar en la guerra al lado de Gran Bretaña y los aliados. Sugirieron, pues, la obtención de ciertas ventajas en Tánger, la expansión de la Guinea española hasta incluir la costa frente a Fernando Po, o la recuperación de las antiguas posesiones de la Micronesia. Propusieron también el fin de la subordinación a Francia en Marruecos ${ }^{69}$. La recuperación de Gibraltar, un sueño acariciado en algún momento, quedaba, sin embargo, fuera de toda cuestión. A pesar de que existieron cálculos sobre una posible permuta de Gibraltar por Ceuta o por alguna parte de Marruecos, esas gestiones no fructificaron y el gobierno británico reafirmó su postura de que estratégicamente Gibraltar era imprescindible para sus intereses y no estaba dispuesto a ninguna cesión ${ }^{70}$.

Finalmente, el Foreign Office desaconsejó el control español de Tánger ante la negativa consideración que les merecía España como potencia colonial y posible administradora de territorios en el Norte de África, calificándoles de cómo gobernantes ineficaces y corruptos, incapaces de sacar provecho económico y desarrollar un puerto internacional, y nefastos en sus relaciones con las tribus nativas, a las que temían que llevaran a la insurrección. Lo único positivo que veían en la presencia española es que

\footnotetext{
${ }^{67}$ TNA, FO 371/3033, Telegrama cifrado del FO a Mr. Vaughan, sin firma, 13 de abril de 1917. En París el embajador británico recibió el encargo de trasmitir el mismo mensaje a su colega español, aunque expresado de una forma más sibilina: "We hear from Madrid that the Spanish Government are seriously considering declaration of war with Germany...We should greatly welcome such a step both for its moral and material effects and you should enquire what action if any they are taking in the matter and whether we can do anything to assist. Confidential: We are not prepared to consider the cession of Gibraltar", TNA, FO 371/3033, Telegrama cifrado del FO. a Lord Bertie, Paris,13 de abril de 1917.

${ }^{68}$ TNA, FO 371/3033, Telegrama cifrado del Foreign Office a Mr. Vaughan, 14 de abril de 1917.

${ }^{69}$ TNA, FO 371/3033, Informe sobre Tánger, sin fecha.

${ }^{70}$ Este cálculo, para el cual se llegó a crear incluso una comisión de estudio, se planteó en abril y diciembre de 1917, y de nuevo en septiembre de 1918, cuando se valoraba cualquier esfuerzo final que ayudara a acabar de ganar la guerra: TNA, ADM 1/8546/334, en abril de 1917 the War Cabinet creó un comité para estudiar el intercambio de Gibraltar por Ceuta. TNA,371/3037, 31 de diciembre de 1917, de nuevo se planteó el intercambio de Gibraltar por Ceuta. TNA, 371/3376, en septiembre de 1918 se estudió una vez más el intercambio de Gibraltar por Ceuta o Marruecos, pero en ninguna de esas ocasiones se llegó a tomar la decisión, a pesar de ser conscientes de que un asunto de tal calibre podría hacer variar la posición española en la guerra.
} 
evitaría el control francés del sur del Estrecho, una situación indeseable para Gran Bretaña: “No hay duda de que los intereses comerciales británicos sufrirían por una cesión a España. Todas las autoridades británicas en Marruecos están de acuerdo en que España es incapaz de administrar correctamente, y mucho menos desarrollar adecuadamente, el puerto de Tánger. Son unánimes al señalar, como resultado de una larga experiencia, que los administradores españoles son ineficaces, incompetentes y corruptos. Bajo administración española Tánger no se mantendrá como el principal puerto del norte de Marruecos. Sólo la solución internacional parece ser práctica desde un punto de vista comercial...Sin embargo, en esta ocasión las consideraciones que deberíamos hacer son políticas y no comerciales... Por otra parte, si España no consigue hacerse con el control de las tribus de la zona y se producen disturbios, Francia puede encontrar la perfecta excusa para intervenir y hacerse con Tánger y con parte de la zona española, con lo cual consolidarían su posición en el Mediterráneo y adquirirían uno de los lados del Estrecho de Gibraltar. Desde el punto de vista británico es importante mantener a Francia fuera del Estrecho... Por otro lado, sabemos el absoluto rechazo de los nativos de Tánger a una administración española y que su inclusión en la zona española implicaría disturbios instigados por las tribus de las montañas que rodean la ciudad. Por todo ello, para Gran Bretaña lo mejor sería la completa internacionalización de Tánger, aunque se podrían ofrecer a España pequeñas concesiones en la organización del municipio, para ponerles en una posición de ligera superioridad en determinadas cuestiones de poca importancia, sin sacrificar la internacionalización de la plaza"11.

Los británicos estudiaron entonces otras posibles iniciativas para presionar a España a fin de que actuara de forma favorable a los aliados. Amenazaron entonces con dificultar el comercio, con no venderles carbón, con un posible bloqueo ${ }^{72}$ : “El asunto del hierro es tan importante y urgente que ningún método debe ser soslayado y no se debe incurrir en retrasos"..."Por todo ello, pido permiso para negociar extraoficialmente con el rey, señalándole que si este país no entra en razón, haremos arreglos en otro sitio, en cuyo caso dejaremos de suministrarles carbón. La sola amenaza de comprar el hierro en América hará que reconsideren su posición" ${ }^{73}$.

Recordaron también al gobierno español que una España simplemente neutral no tendría cabida en la conferencia de paz ni obtendría concesión alguna tras la contienda: "Tenemos que tener mucho tacto a la hora de realizar una intimidación similar..., a fin de evitar que parezca que estamos presionando para que España abandone la neutralidad... Pero, a no ser que usted me diga lo contrario, procuraré presionar en ese sentido en la primera ocasión favorable" ${ }^{74}$.

En cualquier caso, la ilusión duró poco. Romanones se encontró sin apoyos en la cuestión. Los presidentes del Congreso y del Senado y destacados políticos, incluso de su propio partido, se mostraron contrarios a una ruptura de relaciones. En la calle, la opinión mayoritaria se opuso a cualquier conducta que Alemania pudiera considerar inamistosa y pusiera en peligro la seguridad española, obligándoles a entrar en una guerra indeseada.

\footnotetext{
${ }^{71}$ TNA, FO 371/3033, Informe sobre Tánger, sin fecha.

${ }^{72}$ TNA, FO 371/3033, Telegrama cifrado del Foreign Office a Mr. Vaughan,14 de abril de 1917.

${ }^{73}$ TNA, WO 106/5128, Fragmentos de distintas cartas enviadas por Josceline CH. Grant al Colonel BT. Buckley, de la War Office.

${ }^{74}$ TNA, FO 371/ 3033, Hardinge a Balfour, 7 de mayo de 1917.
} 
Tras la dimisión de Romanones el 19 de abril de 1917 y la formación del nuevo gobierno de García Prieto, más proclive a la neutralidad, aunque también favorable a los aliados ${ }^{75}$, los británicos vieron desvanecerse la oportunidad de implicar a España más activamente en la guerra. Por ello concluyeron que "los españoles han interpretado que una ruptura de relaciones suponía la guerra. Lo que España desea es permanecer neutral y jugar un papel importante en la conferencia de paz como la única potencia neutral que se ha mantenido amiga de ambos bandos"76.

En calle seguían abiertas las opciones. El mitin del líder conservador Antonio Maura en la plaza de toros de Madrid, el 29 de abril, refrendó que la única vía sensata para España era la neutralidad ${ }^{77}$. Mientras, los reformistas de Melquiades Álvarez reclamaban en un manifiesto la inmediata entrada en la guerra. El 27 de mayo en un gran mitin de las izquierdas de nuevo en la plaza de toros se pidió la ruptura de relaciones con Alemania, la declaración de simpatías expresas hacia los aliados, e incluso la guerra.

En ese contexto, el agregado militar británico hizo una gestión más cerca del rey. Alfonso XIII manifestó a Grant que le gustaría hacer todo lo posible para ayudar a Su Británica Majestad, aunque siempre dentro de unos límites. Decía Grant: "Me dijo que personalmente, desearía sumarse a los aliados, pero comprendía que esa sería una mala política para el país. Consideraba que podrían prestar una mejor asistencia a Gran Bretaña manteniendo la neutralidad que siendo beligerantes, e incluso señaló los servicios que el cuerpo diplomático y el consular podrían prestar en favor de los aliados". A resultas de la conversación, el agregado militar llegó a la conclusión de que el monarca creía que la guerra llegaría a su fin sin que hubiera una clara victoria de ninguno de los dos bandos, por lo que no deseaba indisponerse con ninguna de las partes en conflicto. Lo que realmente quería era que España desempeñara un importante rol como mediador. Por ello, tras la reunión el agregado aconsejó a su gobierno que había que dejar bien claro al rey que, a pesar de las simpatías que expresaba por los aliados, mientras mantuviera esa actitud tan tibia y equidistante, no habría ningún papel importante para su país en la conferencia de paz ${ }^{78}$.

A su vez, Hardinge, recién retornado a Madrid después de un permiso, informó al Foreign Office de que España era favorable a los aliados, pero temía a Alemania y no iba a hacer nada que pudiera provocarla: "Su Majestad retiró el apoyo a Romanones y se inclinó por un grupo de los liberales partidario de la neutralidad incondicional. Este círculo nos apoyará en tanto sea compatible con la neutralidad, pero no son partidarios de aventuras bélicas ni apoyaran un acuerdo similar al Cortina que exponga a barcos españoles a un ataque alemán que pudiera forzarles a entrar en guerra contra Alemania" ${ }^{79}$. Había que aceptar, pues, que España no se enemistaría con Alemania, pero eso hacía más necesario que nunca trabajar para ganarse la benevolencia española hacia sus intereses.

\footnotetext{
${ }^{75}$ TNA, FO 371/3033, Decypher Mr. Vaughan a Foreign Office, 20 de abril de 1917:" I saw new Prime Minister, who told me that his Government, althoug neutral, were frienddly to Allies and would adhere to agreements of 1902 , 1904 and 1905 and Cartagena Declarations".

${ }^{76}$ TNA, FO 371/3033, Decypher. Mr. Vaughan a Foreign Office, 20 de abril de 1917.

${ }^{77}$ En un discurso calificado por los británicos como "tonto y oscurantista". TNA, FO 1011/117, Carta de Loraine a Herschell, Private and Secret, 1 de mayo de 1917.

${ }^{78}$ TNA, FO 371/3033, 5 de mayo de 1917.

${ }^{79}$ TNA, FO72/3033, Informe de Hardinge al F.O. sobre la situación política que encontró al retornar a su puesto, 2 de mayo de 1917.
} 


\section{RELACIONES ECONÓMICAS: EL ACUERDO CORTINA Y OTROS TRATADOS COMERCIALES}

En 1917, los británicos se ocuparon también de crear un clima favorable a la firma de un tratado comercial. ${ }^{80}$ En la primavera de aquel año, los gobiernos británico y español comenzaron a negociar en secreto en Londres la firma del "Acuerdo Cortina". Debía su nombre al negociador por parte española, José Gómez Acebo, marqués de Cortina, un hombre de negocios bien introducido en los círculos políticos y económicos de los dos países. El representante británico fue el diplomático Sir Maurice de Bunsen. El acuerdo regulaba la venta de hierro, piritas, plomo, wolframio, acero, o cualquier otro mineral español, a Gran Bretaña, sin límite de cantidad y sin derechos de exportación. Fijaba también los productos que se intercambiarían los dos países. Así, España exportaría a Gran Bretaña naranjas, patatas, uvas, plátanos, almendras, vinos y forrajes, así como algodón y yute procedentes de Oriente. A cambio, Gran Bretaña suministraría a España 150.000 toneladas de carbón mensuales, cantidades varias de hojalata, ferromanganeso, sulfato de amonio, acero rápido, maquinaria, productos manufacturados, yute y cáñamo. El acuerdo establecía la utilización de barcos españoles para el transporte, el posible aprovechamiento británico de esos buques, y el reparto de la carga para el beneficio de ambos países. Finalmente, se mencionaba que las dos naciones se prestarían ayuda mutua durante la guerra ${ }^{81}$.

Se redactó un primer borrador del acuerdo en Abril de 1917, pero sus términos no llegaron a prosperar porque despertó tantos recelos en sectores políticos españoles, temerosos de que afectara a su neutralidad, que ni el rey ni el gobierno de García Prieto, formado tras la dimisión de Romanones, se atrevieron a ratificarlo. Los servicios británicos de información detectaron que los alemanes estaban orquestando una campaña en contra de dicho acuerdo a través de la prensa germanófila, a fin de provocar una reacción adversa por parte de la opinión pública española. En El Debate, La Nación, El Correo Español o El Mundo se publicaron artículos denunciando que el acuerdo, arbitrado para el intercambio de hierro por carbón, significaba suministrar contrabando de guerra a Inglaterra. Alertaron, además, de que si los minerales eran enviados en barcos españoles, eso sería motivo para que fueran torpedeados por los alemanes, obligando al gobierno a romper su neutralidad. Señalaron, pues, que lo que se debía hacer era prohibir todo comercio que pusiera en peligro los intereses españoles. La campaña pareció tener efecto porque el nuevo gobierno de García Prieto se manifestó contrario al Acuerdo Cortina, considerando que Alemania se podía sentir agraviada por los términos pactados, lo cual podía poner en peligro los barcos españoles ${ }^{82}$.

El embajador Hardinge propuso entonces pactar el intercambio de productos a través de notas, lo cual constituiría una transacción menos formal que evitaría tener que pasar por el parlamento y enfrentarse a las posiciones de los "ultra neutralistas" en las Cortes. Recomendó adoptar una postura firme advirtiendo que "con el Gobierno de Su Majestad no se juega" y amenazando con cortar el suministro de carbón: "la nación inglesa es paciente y conciliatoria, pero no va a consentir ser toreada ni amenazada, y que, mientras somos indiferentes a si España se resiente o no por el torpedeo de sus barcos por los

\footnotetext{
80 Sobre los antecedentes de este acuerdo y otros aspectos relacionados con el mismo, analizados desde documentación española, consultar C. GARCÍA SANZ, La Primera Guerra Mundial..., pp. 346-354.

${ }^{81}$ TNA, MUN 4/2193.

${ }^{82}$ TNA, FO 371/3033, Vaughan a Balfour, 20 de abril de 1917.
} 
alemanes, no permitiremos que eche por tierra las condiciones en las cuales se desarrolla su comercio con los aliados" 83 .

En esa situación, el agregado militar se entrevistó una vez más con Alfonso XIII. Al indicarle Grant que la no ratificación del Acuerdo Cortina había causado una natural irritación en Inglaterra, el rey respondió que el Marqués de Cortina se había excedido en sus instrucciones y que los términos del acuerdo, tal como se habían redactado, hubieran significado una declaración de guerra en veinticuatro horas por parte de las potencias centrales: "El acuerdo significa poner todos nuestros barcos y los buques alemanes internados en España a disposición de los aliados para que puedan usarlos contra las potencias centroeuropeas. Eso llevaría al inmediato estallido de una guerra entre España y Alemania". El agregado militar añadía que en esa posición pensaba que Alfonso XIII creía que la guerra llegaría a su fin sin que hubiera una clara victoria de ninguno de los dos bandos. Por ello no deseaba indisponerse con ninguna de las partes en conflicto. Lo que realmente quería era que España desempeñara un importante rol como mediador $^{84}$.

Grant se reunió entonces con Cortina, quien le aseguró de su absoluta convicción de que la única actitud posible de Gran Bretaña en el asunto sería rechazar el comercio con España a no ser que ésta ofreciera a los barcos británicos todas las facilidades: "Ha señalado enfáticamente que en ese caso, claudicarían en veinticuatro horas. Las reservas españolas de carbón son muy bajas y el día que no se pueda exportar hierro a los británicos 400.000 mineros se quedarían sin trabajo ${ }^{85 \prime \prime}$.

En esa misma línea, Grant se mostró partidario de presionar al gobierno español para que firmara el acuerdo. Enfatizó que los españoles se encontraban entre el miedo a la amenaza alemana de una declaración de guerra si firmaban el Acuerdo Cortina, y la consciencia de la importancia que para Gran Bretaña tenía el hierro español. También a los españoles les interesaban esas ventas porque, si no se conseguían grandes encargos de hierro, algunos altos hornos tendrían que cerrar, con lo que ello implicaría para la población y la estabilidad del país. Grant indicaba que "la actitud de nuestro embajador es que no debemos mostrar nuestra ansiedad en el asunto porque los españoles aprovecharían para obtener mejores condiciones en sus intercambios. Pero yo creo que debemos ir más allá y presionarles para obtener lo que queremos. El embajador no puede hacerlo por los cauces oficiales, pero yo puedo maniobrar extraoficialmente. He tenido dos largas conversaciones con él y le he persuadido de la vital necesidad de una acción enérgica e inmediata". Señalaba que tenían armas con las que maniobrar, ya que "si dejamos de comerciar con este país durante una semana, habría una revolución aquí. 400.000 mineros serían despedidos inmediatamente y después de unos días muchas de sus fábricas tendrían que detener su trabajo, seguido de cerca de los trenes, con lo cual el caos y la anarquía prevalecerían". Por todo ello, Grant pidió permiso a su gobierno para negociar extraoficialmente con el rey. ${ }^{86}$

En una nueva entrevista, mantenida el 16 de Mayo de 1917, el rey manifestó a Grant que era consciente de la necesidad que tenían los británicos de hierro español, y que sabía que traerlo de Estados Unidos en vez de España costaría más tiempo y más barcos. Señaló que su principal objeción al Acuerdo

\footnotetext{
${ }^{83}$ TNA, FO 371/3033, Informe de Hardinge al F.O., 2 de mayo de 1917.

${ }^{84}$ TNA, FO 371/3033, Entrevista de Grant con el rey, 5 de mayo de 1917.

${ }^{85}$ TNA, FO 371/3033, Entrevista de Grant con el Marqués de Cortina, 7 de mayo de 1917.

${ }^{86}$ TNA, WO 106/5128, Carta de Grant a Buckey, 8 de mayo de 1917.
} 
Cortina era que continuamente mencionaba "Gran Bretaña y sus aliados" y declaró que estaría dispuesto a llegar a un nuevo acuerdo sólo con Gran Bretaña: "No tengo objeción a un acuerdo sólo con Gran Bretaña, y naturalmente Gran Bretaña puede hacer lo que considere necesario para ayudar a sus aliados con lo que obtenga aquí. Pero lo que nosotros no podemos hacer es un acuerdo con los aliados como bloque para suministrarles contrabando de guerra. Sin embargo, me reservo el derecho a negociar con ellos de forma individual, aunque no podría mantener mi posición si hiciera un acuerdo general con los enemigos de las potencias centrales". Tras el preámbulo, el rey descendió a requerimientos muy concretos. Explicó que, a cambio de vender hierro los británicos, España necesitaría que se le asegurara el suministro de 150.000 toneladas de carbón al mes y de 300 toneladas de hojalata. Si Gran Bretaña no aceptaba, ya buscarían otro acuerdo en otra parte. El agregado le contestó que Estados Unidos no podría venderles ese carbón, pues lo necesitaba todo para su propio uso y el de sus aliados, y además, si España no exportaba el hierro que los británicos necesitaban, 4.000 mineros se quedarían sin trabajo. El rey respondió, textualmente, "que no pensara que eran unos locos, que el día que las exportaciones españolas se vieran paralizadas, tres o cuatro mil extranjeros serían expulsados de España y sus trabajos y otros más serían desempeñados por los mineros".. Si Gran Bretaña aceptaba esos requerimientos estaría dispuesto a firmar el acuerdo de forma inmediata ${ }^{87}$.

También Loraine insistió en el asunto. Herschell le había pedido que trasmitiera al rey que la no ratificación del Acuerdo Cortina era contemplada en Gran Bretaña como una desilusión y un nuevo acercamiento de España hacia Alemania, cuando pensaban que después de tanto trabajo parecía que al fin los españoles se inclinaban hacia los aliadófilos. Dada la peculiar relación entre Loraine y el rey, más despreocupada, Alfonso XIII le contestó que no debían preocuparse, que a veces lamentaba tener ministros tan bobos, pero que las cosas acabarían resolviéndose ${ }^{88}$. $\mathrm{Y}$ así fue. Finalmente, el Acuerdo Cortina se ratificó en Diciembre de 1917, al tiempo que se negociaba un acuerdo financiero relativo al crédito mensual que los bancos españoles podrían prestar al gobierno británico.

En la primavera de 1919 se renegoció un segundo acuerdo comercial, en el cual los dos países mantenían el intercambio de productos más o menos en los mismos términos, pero añadían un capítulo financiero ${ }^{89}$ y Gran Bretaña se aseguraba una ventajosa posición para la inversión en infraestructuras y sectores productivos prometedores de cara a la postguerra. Tratados comerciales similares se firmaron también en aquella época con Francia y con Estados Unidos ${ }^{90}$. España se perfilaba ya como un mercado y un campo de inversiones interesante para el futuro y los aliados querían afirmar sus respectivas posiciones.

\section{LA ESTABILIDAD DEL PAÍS EN UN TIEMPO DE CRISIS}

En los meses de mayo y junio de 1917, los representantes británicos en España advirtieron que las posiciones de extrema prudencia adoptadas por los españoles estaban influidas por los sucesos en Rusia y

\footnotetext{
${ }^{87}$ TNA, FO 371/3033, Informe de Grant sobre una nueva entrevista con el rey, 16 de mayo de 1917.

${ }^{88}$ TNA, FO 1011/278, Carta de Loraine a Hershell, 20 de junio de 1917.

${ }^{89}$ TNA, MUN 4/2194.

${ }^{90}$ GONZÁLEZ CALLEJA y AUBERT, Nidos de espías..., pp. 96-99: Acuerdo franco-español de 6 de marzo de 1918. Jean-Marc DELAUNAY, "Relaciones franco-españolas en torno a la Primera Guerra Mundial”, Mélanges de la Casa de Velázquez, 18 (1982), p. 137. José Antonio MONTERO, “Diplomacia económica y balanza de pagos: los pactos estadounidenses de 1918”, Revista de Historia Económica, 2 (2008), pp. 243-276.
} 
el fin del segundo frente. El rey, persuadido por los germanófilos y por las influencias filo-austriacas que le rodeaban en la Corte, creyó que la revolución rusa iba a tener consecuencias desastrosas para los aliados. Rusia abandonaría la guerra, lo cual permitiría a Alemania trasladar más fuerzas al frente occidental, y forzaría la conclusión de la paz. Ante esa posibilidad el rey consideró que España no debía indisponerse con los alemanes. Enfrió sus relaciones con los aliados y se mostró más distante que nunca. La opinión pública también se vio influida por los temores al impacto de la revolución rusa y los rumores de que Italia pensaba abandonar la lucha ${ }^{91}$.

Durante una conversación con Hardinge, Alfonso XIII le trasmitió su pesimismo ante la situación que se vivía en Rusia, lamentándose de la decadencia de un imperio que fue tan grande y poderoso, y en especial de la deserción del ejército, de la nobleza y de la propia familia imperial, que dejaron al emperador totalmente solo. -Decía el rey-:"No había habido entre ellos ni un solo caballero que hubiera tenido el valor de arriesgar su piel para defender al zar. ¿Puede imaginarse que si la revolución hubiera tenido lugar en España o en Gran Bretaña no hubiera nadie capaz de defenderme a mí o a su soberano?" "Le contesté", respondía Hardinge-, "que, felizmente, esos hechos hubieran sido imposibles en Inglaterra, pero que si ocurrieran los leales ingleses hubieran luchado por su rey, tal como hicieron en los días de la Gran Rebelión. Rusia es, sin embargo, un país semi-asiático en el que es difícil aplicar las ideas y la moral de Occidente". El rey temía también que la revolución se extendiera a Italia. Estaba preocupado por este país, ya que pensaba que la Corte en Roma, la clase alta y el ejército deseaban llevar la guerra hasta una conclusión victoriosa, pero las masas parecían cansadas del conflicto y en esa situación la influencia socialista podía ejercer en Italia la misma perniciosa influencia había ejercido en Rusia ${ }^{92}$.

En esa tesitura Hardinge resaltó la importancia que tenía la posición del rey: "El elemento más preocupante de la presente crisis es la posición personal del rey. Su Majestad es un príncipe capaz y patriótico, pero es cambiable y muy fácilmente manipulable. Fue "todo" en la Misión Cortina y en el acuerdo subsiguiente, pero el colapso de Rusia cambió sus perspectivas. Los argumentos introducidos por el Colonel Kalle, apoyados por las influencias austriacas de la Corte, le persuadieron de que una victoria aliada era muy dudosa, y que haría bien de inclinarse hacia una dirección más pro-alemana. Por ello sacrificó a Romanones y a Cortina y dio su confianza al partido democrático., ${ }^{93}$

También Loraine trabajó cerca del monarca en ese momento delicado. En varias entrevistas mantenidas en el verano de 1917 Alfonso XIII le manifestó su preocupación por la revolución rusa y su conexión con las huelgas en España, un país susceptible a que la revolución se extendiera rápidamente debido a las desigualdades y a los descontentos sociales. Loraine advirtió a su gobierno de que los líderes revolucionarios estaban trasmitiendo a idea de que los ingleses que no tenían nada que ganar de una España monárquica, mientras que una España revolucionaria se inclinaría más fácilmente hacia los aliados. Era necesario desmentir públicamente esos mensajes subversivos con artículos en los principales

\footnotetext{
${ }^{1}$ TNA, FO 371/3033, Vaughan al Foreign Office, 17 de abril de 1917: "Many persons in Spanish Society and Court circles were rendered very nervous by the events in Russia and our prompt recognition of the Provisional Government.. [It] was interpreted here as an encouragement to those who favoured a republican form of Government, and did not predispose Spanish Society in our favor".

92 TNA, FO 371/3033, Informe de Hardinge al Foreign Office sobre una conversación mantenida con Alfonso XIII, 19 de mayo de 1917.

93 TNA, FO 371/3033, Carta de Sir A. Hardinge a Lord Robert Cecil, 12 de junio de 1917.
} 
periódicos e incluso desde la Cámara de los Comunes. Además, en una nueva reunión en el campo de polo, Loraine aseguró al rey que ni Francia ni Gran Bretaña tenían nada que ver con los movimientos revolucionarios ni los apoyaban de ningún modo. ${ }^{94}$

A los británicos les preocupó igualmente una posible deriva que condujera al desafecto hacia Gran Bretaña. A ello contribuyó que, en aquellos complicados meses de la primavera y el verano de 1917 de huelgas y enfrentamientos, los alemanes aseguraran que tras todos esos incidentes se encontraban los británicos, que deseaban provocar movimientos que pudieran conducir a la proclamación de una república presidida por Romanones y, por tanto, favorable a un mayor compromiso con Gran Bretaña. Los diplomáticos británicos negaron tajantemente las acusaciones. ¿Cómo un país tan amante de la estabilidad y el orden como Gran Bretaña iba a apoyar movimientos revolucionarios? ¿Cómo la nación monárquica por antonomasia iba a fomentar la caída de la monarquía en España? Ellos, cuyo principal interés eran los minerales españoles, ¿cómo iban a propiciar unas huelgas que impedían la extracción y el transporte de un hierro vital para su esfuerzo bélico? En ese momento todo su esfuerzo se concentró en negar su implicación en los sucesos que convulsionaban España.

Realizaron también una firme defensa de la monarquía española en tanto que garante de la estabilidad y elemento de unión entre los españoles. Ante el mitin que la izquierda española celebró en la Plaza de Toros de las Ventas en mayo de 1917 y las críticas que allí se vertieron sobre el soberano, las autoridades británicas realizaron una defensa cerrada de la monarquía, asegurando que no sería deseable un gobierno republicano en España. Hardinge escribió a Lord Robert Cecil asegurándole que "sería muy poco afortunado que las simpatías de nuestros amigos de extrema izquierda hicieran que se identificara a los gobiernos aliados con los problemas domésticos del republicanismo. Ha pasado medio siglo desde la restauración de la Casa de Borbón en la persona de Alfonso XIII, que puso fin a la sangrienta anarquía que la generación más anciana de los españoles identifica con los dos años de régimen republicano... Es verdad que, a pesar del espíritu de paz y de progreso de los últimos cincuenta años, todavía queda mucho por hacer en España, que hay que remediar una peligrosa condición social, pero el sentimiento general de los hombres de pensamiento es que eso se puede conseguir sin un cambio de régimen y sin desacreditar o debilitar la autoridad del soberano, que es la personalidad más popular del país"95.

En la misma carta de Hardinge a Cecil, se hablaba también de que la propaganda alemana contra Gran Bretaña estaba causando la impopularidad de este país en España. Rumores expandido por los alemanes afirmaban que los ingleses alentaban la revolución y no querían firmar la paz, mientras que el resto de los beligerantes sí lo deseaba, y que con esa actitud estaba obligando a las mujeres y a los niños de los países en guerra, y a los propios españoles, a grandes sufrimientos y penalidades. La culpa de todo, decían los alemanes, la tenían el imperialismo y el militarismo británico.

Ante el rápido reconocimiento británico del nuevo gobierno revolucionario de Petrogrado, Hardinge advirtió que se extendían "rumores malintencionados de que Sir George Buchanan", - el embajador británico en Rusia- "conspiraba en secreto contra el zar; que la pérfida y cínica política de Inglaterra es alentar la revolución y el desgobierno en España, al igual que ha hecho en otros países -otra vez la vieja leyenda de la pérfida Albión-, para así desangrar y debilitar a los españoles para poder hacer con

\footnotetext{
${ }^{94}$ TNA, FO 371/278, Cartas de Loraine a Herschell, 20 de junio, 3 de julio y 7 de julio de 1917.

${ }^{95}$ TNA, FO 371/3033, Carta de Hardinge a Lord Robert Cecil, 29 de mayo de 1917.
} 
ellos lo que sea. El rey y la reina de España están indignados con esas calumnias, pero hay otros círculos en los que se le da crédito" ${ }^{\prime 6}$.

Especial preocupación les mereció a los británicos la influencia que la propaganda alemana estaba teniendo sobre Alfonso XIII, en gran medida por sus buenas relaciones con los agregados alemanes y austriacos. Tal como advertía Grant, "si tal circunstancia es grave en todo el país y todos los círculos sociales, es especialmente adversa en el caso del rey, porque el monarca es una pieza clave en las decisiones políticas". Tras una entrevista mantenida con Alfonso XIII en mayo de 1917, el agregado militar insistió en la necesidad de contrarrestar la información que los alemanes están suministrando al rey, proporcionándole otras noticias más ajustadas a la realidad y más favorables a su causa: "es importante que el rey tenga una justa apreciación de la realidad. Todavía estoy convencido de que sus simpatías están con los aliados, pero está demasiado presionado por los alemanes. He intentado organizar a los agregados militares para que soliciten audiencia con el rey y refuercen la posición aliada en la guerra, pero solo el francés tiene fuerza para ello"... Grant se quejaba de que el rey mantenía frecuentes entrevistas con el agregado militar alemán en Madrid, Colonel Kallé, y con el agregado militar de España en Berlín, un entusiasta admirador de los alemanes y de todo lo alemán, persona con la que el monarca tenía una gran confianza. Estas fuentes le habían hecho creer: que Francia estaba totalmente exhausta y no podría resistir mucho; que los efectos del bloqueo llevarían a Gran Bretaña a la postración; que Alemania iba a iniciar una gran ofensiva contra Italia, lo cual obligaría a este país a firmar una paz separada; que Rusia ya había decidido firmar la paz por su cuenta; $y$, finalmente, que, aunque las potencias centrales estaban en condiciones de ganar la guerra por completo, y de aguantar más que los aliados, eran partidarias de llegar a una paz basada en el mantenimiento del statu quo ante. En definitiva, estos informadores le estaban trasmitiendo la impresión de que la victoria aliada era incierta, con lo cual el rey era aún más reacio a hacer nada que pudiera molestar a Alemania, a quien consideraba un posible vencedor en la contienda. Por ello, Grant insistía en que era necesario contrarrestar esas noticias y trasmitirle informaciones ciertas de la situación de la guerra, para lo cual sugería utilizar el cauce del secretario privado y confidencial del rey, Sr. Emilio de Torre, cuyas simpatías estaban con los aliados ${ }^{97}$.

En esa situación, el embajador británico decidió publicar en La Época, el 4 de junio de 1917, un artículo firmado por "Un Diplomático aliadófilo", en el que trataba de contrarrestar la mala imagen que de Gran Bretaña se estaba intentando difundir desde círculos germanófilos. Hardinge declaró al respecto, "Un movimiento republicano no sería, sin embargo, ventajoso en modo alguno para nosotros. Una revolución en España, aún suponiéndola muy improbable, dado el carácter y la popularidad tan merecida de $\mathrm{S}$. M. el rey, en la hipótesis de que por un momento podría triunfar, produciría inevitablemente la guerra civil, y ésta sería tan peligrosa a los aliados como la campaña submarina, dado que el principal servicio que España les presta, y especialmente a Inglaterra, es la venta de sus productos, particularmente de sus minerales, y es obvio que cualquier perturbación, análoga por ejemplo a la de 1873, la debilitaría para poder ofrecer este auxilio"..."Los objetivos militares y los intereses egoístas de los aliados requieren una España próspera y tranquila. Aparte de esas consideraciones, sería difícil convencer a un chico inteligente de que el Rey de Inglaterra y un ministro de Estado conservador, como Mr. Balfour, sean tan fanáticos republicanos que se

\footnotetext{
96 Ibídem.

${ }^{97}$ TNA, FO 371/3033, Grant al Foreign Office, 7 de mayo de 1917. TNA, WO 106-5128, Grant al Colonel BT. Buckley, de la War Office.
} 
mostraran dispuestos a sacrificar los intereses del Ejército inglés al placer de destronar a los parientes españoles de S.M. Británica" ${ }^{98}$.

\section{PROPAGANDA Y CONTRAPROPAGANDA EN LA GUERRA Y LA POSTGUERRA}

Aun así, a esas alturas de la guerra, los desmentidos no parecían suficiente. A pesar de que la opción de que España participara más activamente en el conflicto se había desvanecido, y con la mirada puesta ya en el fin del esfuerzo bélico y en el futuro posterior, con objeto de estrechar los lazos entre los dos países los británicos se trazaron como objetivo "crear una comunidad de intereses industriales, comerciales y financieros entre Gran Bretaña y España", y para ello intensificaron las labores de propaganda y contrapropaganda ${ }^{99}$.

Era esa una faceta que se había ido incrementado a lo largo de la guerra ${ }^{100}$. Por una parte, fue necesario contrarrestar las activas campañas de los alemanes contra los aliados ${ }^{101}$, así como analizar, desmentir y contraatacar la información de los periódicos germanófilos ${ }^{102}$. Por otra, se fomentó una propaganda constructiva de carácter político, económico, comercial y cultural, a fin de acrecentar las afinidades entre España y Gran Bretaña. Varios departamentos, entre ellos el War Propaganda Bureau y el Committee for Propaganda in Enemy Countries, elaboraban todas las semanas un boletín marcando las pautas que debían desarrollarse en cada país ${ }^{103}$. Tenían un equipo dedicado a redactar unos panfletos muy elaborados, así como a difundir libros, ilustraciones fotografías y películas en los que se alababan las virtudes británicas y los valores de la causa aliada ${ }^{104}$. John Walter, representante en Madrid del periódico The Times, director de la Agencia Anglo-lbérica fue encargado de las relaciones con los medios de comunicación y de desarrollar las labores de propaganda y contrapropaganda en España. Además de varios

98 TNA, FO 371/3033, Comentarios de Hardinge al Foreign Office sobre el artículo "Un Diplomático aliadófilo", publicado en La Época el 4 de junio de 1917.

99 TNA, FO 1011/117, Carta de Percy Loraine a Eric Hambro. 29 de abril de 1918, proponiendo líneas y métodos de propaganda y contrapropaganda. Informaba de que había tenido una conversación con el duque de Alba, en el que éste le había aconsejado que promovieran la publicación de textos de escritores españoles aliadófilos muy conocidos Subrayaba también que debían hacer una propaganda constructiva no solo para la guerra, sino también para después, creando una verdadera comunidad de intereses económicos, industriales y comerciales entre Gran Bretaña y España. Señalaba como esferas de actuación de especial interés las manufacturas de maquinaria eléctrica, los astilleros para la construcción de barcos y maquinaria marítima; los transportes y comunicaciones, y en concreto ferrocarriles. Insistía en la idea de incorporar a España al bloque de países de Europa Occidental, señalando que España, por su estratégica posición y su relación con América Latina podía servirles en el Oeste de la misma manera que Turquía les servía en el Este, sugiriendo la concesión de algún territorio en el norte de África para que sintiera que aún era una gran potencia. Esas actuaciones podrían inclinar a España hacia Gran Bretaña..

${ }^{100}$ C. GARCÍA SANZ, La Primera Guerra Mundial..., pp. 131-198.

101 TNA, FO 371, 3033, Vaughan al Foreign Office, 15 de abril de 1917. En esa fecha Vaughan informaba de que se estaba haciendo una importante labor de propaganda alemana contra Gran Bretaña cerca de la Reina Madre, la aristocracia, el clero y los carlistas, insistiendo en que Inglaterra quería convertir a España en una colonia y acabar con el catolicismo en el país: "el fin es germanizar a España”.

102 Entre los cuales identificaban a El Correo Español, La Nación (editada por el Marqués de Polavieja), La Acción (órgano del señor Maura), Tiempo, Unión, España Nueva, El Día, La Tribuna, ABC o El Mundo.

${ }^{103}$ TNA, FO 371/4359, Political Intelligence Department. FO 371/3372.

${ }^{104}$ TNA, FO 185/1337, Propaganda, elaboración de folletos, catolicismo en España y Gran Bretaña... 
agentes dedicados específicamente a la cuestión, tuvo la ayuda de los diplomáticos de la embajada, los distintos agregados, los cónsules y vice-cónsules que se encargaron de las relaciones cotidianas con las instituciones y los ciudadanos españoles en sus distintos destinos ${ }^{105}$.

A fin de acrecentar la afinidad entre los dos países estudiaron la creación de un Bureau de Información anglo-británico ${ }^{106}$, se ocuparon de asuntos tales como dar a conocer los cuadros de Velázquez que había en Gran Bretaña, para demostrar que se interesaban por la cultura española y con ello despertar las simpatías de los españoles, difundir la escuela británica de pintura, y en especial de pintores como Gainsborough, Reynolds y Rommey ${ }^{107}$, o a destacar los muchos católicos había en Inglaterra y cómo esta confesión también podía ser un vínculo entre ambas sociedades ${ }^{108}$. De igual forma, se fomentó la creación de una Sociedad Hispano-Británica que pudiera estrechar los lazos entre los dos países ${ }^{109}$.

Por otra parte, a fin de conocer bien el pulso del país, el Political Intelligence Department del Foreign Office elaboraba una relación semanal de los artículos que determinados intelectuales españoles publicaban en la prensa española, diciendo donde se publicaban y cuál era su contenido. Entre los intelectuales citados todas las semanas por este departamento se encontraban Salvador de Madariaga ( $E$ I Liberal, España), Ramiro de Maeztu (Correspondencia de España, El Nuevo Mundo, La Prensa), Luis Bonafoux (El Heraldo de Madrid, Diario de Marina, El Liberal), Ramón de Belausteguigoitia (El Sol, Euzkadi), Oscar Correia (Industria y Comercio), Manuel Barroso (EI Mundo), Ricardo Gasset (editor de El Imparcial), Luis A. Bolin, Luis Gómez de Mendoza (La Epoca, El Universo), Luis Araquistain (España) ${ }^{110}$.

En la primavera de 1918, Loraine y Grant recomendaron que se creará una Oficina de Propaganda Comercial, encargada de convencer a los españoles de que los socios económicos más convenientes para España, tanto durante la guerra como después, eran los países aliados, y muy particularmente Gran Bretaña. Con ellos debían tramitar los intercambios comerciales, las inversiones, los préstamos, la mejora de sus transportes y comunicaciones, la modernización de sus industrias y su maquinaria. Percy Loraine negoció sobre el asunto con Eric Hambro, responsable del Ministerio de Información para la propaganda en todos los países neutrales ${ }^{111}$. A su vez, Grant discutió los términos de esa oficina con Buckey en la War

\footnotetext{
${ }^{105}$ TNA, FO 185/1433, Circular de Hardinge al servicio consular, 17 de enero de 1917.

${ }^{106}$ TNA, FO 1011/117, Carta de Hambro a Loraine, 10 de junio de 1918, "Instructing Walter; I have told him to cat a great deal on your suggestions, though I have not informed him that they emanate from you"..."The most important part is the setting up of a Bureau of Information, which I have suggested should be called the AngloSpanish Bureau of Information... for the purpose of exhibiting photographs showing British industries, etc. in this country and the colonies. Attached to this will be a library with books of reference on all trade questions, Science, etc..." Desarrolla a continuación proposiciones para el funcionamiento de ese Bureau.
}

${ }^{107}$ TNA, FO 1011/117, Carta de Loraine a Hambro, 5 junio 1918, "I have discussed both ideas with the Duke of Alba and D. Aureliano Beruete... and both are in hearty agreement with the suggestion"

${ }^{108}$ TNA, FO 185/1337, 1917.

${ }^{109}$ TNA, FO 371/3035, 28 Noviembre 1917 y 22 Diciembre 1917.

${ }^{110}$ TNA, F0371/4361, Political Intelligence Department.

${ }^{111}$ TNA, FO 1011/117. El 9 de agosto de 1918, Loraine escribió a Hambro señalando la conveniencia de crear un Bureau de Propaganda Comercial en España: "Spain is one of the few countries which has remained neutral throughout the war. It is a country rich in mineral wealth. It is a country fully worth commercial attention and development. The German realized this fact some time ago. He will need some markets and sources of supply 
Office, quien le dirigió al M.I. 2, al D.M.I. y a Lord Beaverbrook, en tanto que ministro de Información y encargado máximo de las labores de propaganda británica ${ }^{112}$.

Quizás por este último esfuerzo británico, quizás porque la lógica de los acontecimientos, de las inversiones y de los intereses llevaba a ello, España permaneció económicamente ligada a Gran Bretaña y a Francia después de la guerra y estos países fueron claves en la modernización de sus estructuras, aún sin alcanzar muchas de las ventajas conseguidas por los países aliados que habían intervenido en la Gran Guerra.

\section{CONCLUSIONES}

A través del análisis de la documentación manejada y los temas tratados en este artículo se puede concluir que a Gran Bretaña le hubiera interesado un mayor compromiso de España en el esfuerzo bélico de los aliados, que se hubiera podido vestir de distintas formas, como una simple ruptura con Alemania, como una colaboración con los aliados más o menos reconocida, o como una participación activa en la guerra. En un principio el gobierno británico no se mostró demasiado dispuesto a asumir los costes de una participación bélica española directa, ni las garantías de defensa del territorio español que ello hubiera implicado. Las fuerzas militares y navales españolas eran demasiado débiles para significar una gran ayuda y ya tenía asegurado el apoyo estratégico de Portugal y de sus islas en el Atlántico. Ahora bien, el transcurso de la guerra, mucho más larga de lo esperado, la entrada en la contienda de los Estados Unidos, la necesidad de adquirir productos necesarios para el esfuerzo bélico, la dura batalla marítima y submarina que se estaba librando en aguas españolas, la revolución rusa de 1917 y la evolución de los frentes de batalla hicieron que Gran Bretaña concediera una importancia creciente a España y trabajara activamente por asegurarse el apoyo español. El gobierno británico no contempló la posibilidad de una España estrictamente neutral y ajena al conflicto. Cada vez que se planteó la potencial entrada de España en la guerra, de una manera u otra, en un momento o en otro, 1914 o 1917, las distintas instancias británicas manifestaron su interés por una mayor participación española en la contienda, en especial si era una iniciativa que partía del propio gobierno español. Por ello estudiaron fórmulas para hacer menos gravosa una participación española más activa, o para ofrecer compensaciones que incentivaran la entrada de España en la guerra. Al no poder conseguirlo, los representantes británicos en España, a través de distintos cauces y organismos, no cejaron en el objetivo de conseguir el apoyo español en los temas que les interesaban y de evitar la colaboración española con Alemania y los países centrales de Europa. La presión británica para conseguir de España todo aquello que necesitó durante la guerra fue constante, como lo fue

after the war, and cannot expect to find them in countries which have already broken off diplomatic relations or otherwise declare themselves as hostile to Germany..."Is evidence that Spain is preparing herself for momentous decisions and that we should not be behind her to form a correct opinion and take favorably decisive actions"

El 12 de agosto de 1918, Hambro, responsable de la propaganda en América Látina, España y Escandinavia en el ministerio de Información, escribió a Loraine sobre los planes para crear efectivamente una oficina de Propaganda Comercial, la idoneidad de Villiers para ese cargo y los trámites que deberían seguir para conseguirlo.

112 TNA, WO 106/5128, Carta de Buckley a Grant, 15 de abril de 1918, “Could you give me further details on how you propose for the plan to work. Right now, it's a bit vague. What reports do you propose should be bought? Will you be using commercial agents to distribute the propaganda in the process of their regular business dealings or will special agents be used? Do you need special literature to be prepared? Will it be done throughout Spain? What are the main points on which you believe the propaganda should be based? Is the ultimate goal for Spain to break off relations with Germany or to promote trade after the war? ..." 
también la política desarrollada para contrarrestar las acciones alemanas en la Península y en sus archipiélagos. España no participó en la guerra, pues, pero durante la contienda en su territorio se libraron mil batallas en las que quizás no hubo tiros ni trincheras, pero que supusieron un esfuerzo bélico importante por parte de los británicos y una respuesta positiva por parte española.

Sin embargo, España no acabó de decidir una entrada abierta en la guerra. En muchos momentos trabajó por los intereses de los aliados y colaboró claramente con los británicos. El rey mostró su simpatía por su causa y algunos políticos hubieran estado dispuestos a un mayor compromiso. Pero otros muchos no lo estuvieron y la opinión pública era mayoritariamente contraria a la participación en el conflicto. También pesaron los lazos con Austria-Hungría y con Alemania. Al final la opción más conservadora fue la neutralidad, disfrazada si se quiere de una "neutralidad aliada" llena de complicidades con Gran Bretaña.

A partir de la segunda mitad de 1917, la opción se inclinó por rentabilizar las ventajas de esa neutralidad amistosa. El gobierno español subrayó que España era el mayor y más importante de los neutrales, que tenía buenas relaciones con los dos bandos contendientes y que esperaba que esas circunstancias le convirtieran en un óptimo mediador y como tal pudieran obtener compensaciones en la paz. Apostó por estar en la mesa de negociaciones, y por ello decidió no indisponerse con ninguno de los dos bandos y acabó la guerra como neutral. Pero como bien se había dicho, había "neutralidades que matan" y como los británicos se encargaron de recordarles "una España simplemente neutral no tendría cabida en la conferencia de paz"113. A pesar de la ayuda prestada a Gran Bretaña durante la contienda y de la guerra encubierta que se libró en la Península, la neutralidad oficial tuvo un precio.

Ello no impidió, no obstante, que a lo largo de la guerra, y aún más en los últimos meses de la contienda, los británicos trabajaran para inclinar a España hacia la órbita de Gran Bretaña a fin de conseguir una situación ventajosa para hacerse con el mercado y las inversiones que la Península iba a necesitar para modernizar su economía y sus infraestructuras en el mundo de la postguerra.

${ }^{113}$ TNA, FO 371/3033, Hardinge a Balfour, 7 de mayo de 1917. 